\title{
Immune Response to Rotavirus and Gluten Sensitivity
}

\author{
Antonio Puccetti $\mathbb{D}^{1},{ }^{1,2}$ Daniele Saverino $\mathbb{D D}^{3}{ }^{3}$ Roberta Opri, ${ }^{4}$ Oretta Gabrielli, ${ }^{4}$ \\ Giovanna Zanoni, ${ }^{4}$ Andrea Pelosi, ${ }^{1}$ Piera Filomena Fiore, ${ }^{1}$ Francesca Moretta, ${ }^{5}$ \\ Claudio Lunardi (D), ${ }^{5}$ and Marzia Dolcino $\left.{ }^{5}\right)^{5}$ \\ ${ }^{1}$ Immunology Area, Pediatric Hospital Bambino Gesù, Viale San Paolo 15, 00146 Rome, Italy \\ ${ }^{2}$ Department of Experimental Medicine, Section of Histology, University of Genova, Via G.B. Marsano 10, 16132 Genova, Italy \\ ${ }^{3}$ Department of Experimental Medicine, Section of Human Anatomy, University of Genova, Via De Toni 14, 16132 Genova, Italy \\ ${ }^{4}$ Immunology Unit, University Hospital of Verona, Piazzale L.A. Scuro 10, 37134 Verona, Italy \\ ${ }^{5}$ Department of Medicine, University of Verona, Piazzale L.A. Scuro 10, 37134 Verona, Italy
}

Correspondence should be addressed to Marzia Dolcino; marziadolcino@gmail.com

Received 31 July 2017; Revised 18 December 2017; Accepted 25 December 2017; Published 15 March 2018

Academic Editor: Peirong Jiao

Copyright (c) 2018 Antonio Puccetti et al. This is an open access article distributed under the Creative Commons Attribution License, which permits unrestricted use, distribution, and reproduction in any medium, provided the original work is properly cited.

\begin{abstract}
Rotavirus is a double-stranded RNA virus belonging to the family of Reoviridae. The virus is transmitted by the faecal-oral route and infects intestinal cells causing gastroenteritis. Rotaviruses are the main cause of severe acute diarrhoea in children less than 5 years of age worldwide. In our previous work we have shown a link between rotavirus infection and celiac disease. Nonceliac gluten sensitivity (NCGS) is emerging as new clinical entity lacking specific diagnostic biomarkers which has been reported to occur in $6-10 \%$ of the population. Clinical manifestations include gastrointestinal and/or extraintestinal symptoms which recede with gluten withdrawal. The pathogenesis of the disease is still unknown. Aim of this work is to clarify some aspects of its pathogenesis using a gene array approach. Our results suggest that NCGS may have an autoimmune origin. This is based both on gene expression data (i.e., TH17-interferon signatures) and on the presence of TH17 cells and of serological markers of autoimmunity in NCGS. Our results also indicate a possible involvement of rotavirus infection in the pathogenesis of nonceliac gluten sensitivity similarly to what we have previously shown in celiac disease.
\end{abstract}

\section{Introduction}

Nonceliac gluten sensitivity (NCGS) can be defined as a nonallergic condition in which the consumption of gluten can lead to symptoms similar to those observed in celiac disease (CD). NCGS is characterized by the absence of celiac specific antibodies (against tissue transglutaminase, endomysium, and/or deamidated gliadin peptide) and absence of classical enteropathy (Marsh 0-1) although an increased density of $\mathrm{CD} 3+$ intraepithelial lymphocytes can be observed in duodenal biopsies. Patients with NCGS may have variable HLA status, and positivity for HLADQ2 and/or DQ8 has been found in roughly 50\% of patients with NCGS. Serological analyses of NCGS patients revealed a high prevalence $(40-50 \%)$ of first generation antigliadin IgG antibodies. NCGS is characterized by symptoms that usually occur soon after gluten ingestion and disappear or improve with gluten withdrawal but relapse following gluten challenge. The clinical presentation of NCGS may be a combination of gastrointestinal symptoms, including abdominal pain, bloating, bowel habit abnormalities (diarrhoea or constipation), and systemic manifestations, that is "foggy mind," fatigue, muscle and joint pain, leg or arm numbness, eczema and skin rash, depression, and anemia. Similarly to patients with $\mathrm{CD}$, subjects with clinical manifestations compatible with NCGS should start a gluten-free diet. Since it is still not clear whether NCGS is a permanent or transient condition, reintroduction of gluten after 1-2 years on a glutenfree diet can be considered $[1,2]$. 
Rotavirus is a double-stranded RNA virus belonging to the family of Reoviridae.

The virus is transmitted by the faecal-oral route and infects intestinal cells causing gastroenteritis. Rotaviruses are the main cause of severe acute diarrhoea in children less than 5 years of age worldwide [3]. They are responsible for 453,000 deaths worldwide each year, which in most cases $(85 \%)$ occur in developing countries [3]. The virus particle is composed of six viral proteins (VPs) called VP1, VP2, VP3, VP4, VP6, and VP7. Among these, the glycoprotein VP7 is located on the outer surface of the virus determining the specific G-type of the strain and plays a role in the development of immunity to infection [4].

We have previously described the presence, in active celiac disease (CD), of a subset of antitransglutaminase IgA antibodies that recognizes the viral protein VP-7 and is able to increase intestinal permeability and induce monocyte activation [5]. We then showed that the antirotavirus VP7 antibodies may be even detected before the CD onset and the detection of antitissue transglutaminase (tTG) and antiendomysium antibodies, showing a predictive role [6]. In addition, we observed that these antibodies were able to induce in human T84 intestinal cell line the modulation of genes involved in biological processes that represents typical features of CD [6]. Taken together, our data seem to provide a link between rotavirus infection and CD.

In this paper, we aim at clarifying some aspects of the pathogenesis of NCGS by a gene-array approach. In particular, we plan to verify the possibility of the involvement of an autoimmune mechanism in the disease. In addition, we also aim at investigating a possible involvement of rotavirus infection in the development of NCGS. For this purpose, we compared the global panel of modulated genes in NCGS to the dataset of human T84 intestinal cells treated with antirotavirus VP7 antibodies, described in our previous work [6], and to a dataset of acute phase of rotavirus infection, downloaded from the GEO (Gene Expression Omnibus) database, searching for transcriptional profiles that may be associated to viral infection.

\section{Materials and Methods}

2.1. Patients. We studied a cohort of 16 patients (6 males and 10 females, mean age: 27.3 years) affected by NCGS, attending the Unit of Autoimmune Diseases and the Immunology Unit and Child Neuropsychiatry Unit at the University Hospital of Verona, Italy.

All the enrolled subjects were recruited after informed consent. Main symptoms were headache, dermatitis, chronic urticaria, muscle and joint pain, bloating, abdominal pain, diarrhoea, alternating bowel movements, and fatigue in a variable combination.

Diagnosis of NCGS was established when all the following criteria were met: (1) exclusion of wheat allergy by clinical history and determination of specific IgE; (2) exclusion of celiac disease by absence of celiac-specific antibodies tissue transglutaminase (tTG), endomysium (EMA), and/or deamidated gliadin peptides (DGP); (3) duodenal biopsy with a histological damage grade 0 to 1 , according to Marsh's classification; (4) significant improvement of symptoms on strict gluten-free diet and relapse of symptoms after gluten reintroduction.

2.2. Detection of Anti-VP7 Peptide Antibodies. The ELISA test for antibody binding to the synthetic peptides has been carried out as already described elsewhere with minor modifications [7]. The synthetic peptides were used at a concentration of $20 \mu / \mathrm{mL}$ in PBS to coat polystyrene plates (Immulon 2HB, Thermo). For the detection of antirotavirus VP7 peptide IgA antibodies, only the sera whose $O D$ readings were higher than the mean plus three standard deviations of each serum dilution of the control group were considered positive. OD values higher than 0.140 were considered positive.

2.3. Gene Array. Peripheral blood cells were collected for analysis of gene expression profiles on a gluten-containing diet. PAXgene Blood RNA tubes (PreAnalytiX, Hombrechtikon, Switzerland) were used for blood collection and total RNA was extracted according to the protocol supplied by the manufacturer. Preparation of cRNA hybridization and scanning of arrays for each samples were performed following the manufacturer instructions (Affymetrix, Santa Clara, CA, USA) by Cogentech Affymetrix microarray unit (Campus IFOM IEO, Milan, Italy) using the Human Genome U133A 2.0 GeneChip (Affymetrix). The gene expression profiles were analysed using the GeneSpring software version 12.1 (Agilent Technologies, Santa Clara, CA, USA) that calculated a robust multiarray average of background-adjusted, normalized, and log-transformed intensity values applying the robust multiarray average algorithm (RMA). The normalized data were transformed to the $\log _{2}$ scale. The unpaired $t$-test was performed to determine which genes were modulated at a significant level $(p \leq 0.01)$, and $p$ values were corrected for multiple testing by using Bonferroni correction. Finally, statistically significant genes were chosen for final consideration when their expression was at least 1.5-fold different in the test sample versus control sample. Genes that passed both the $p$ value and the FC restriction were submitted to functional and pathway enrichment analysis according to the Gene Ontology (GO) annotations employing the Panther expression analysis tools (http://pantherdb.org/).

\subsection{Protein-Protein Interaction (PPI) Network Construction} and Network Modular Analysis. All the possible interactions among the protein products of DEGs were analysed with Search Tool for the Retrieval of Interacting Genes (STRING version 1.0; http://string-db.org/) a web-based database that includes experimental as well as predicted interaction information and covers more than 1100 sequenced organisms. Only protein-protein interaction (PPI) pairs that were confirmed by experimental studies were selected, and a score of $\geq 0.7$ for each PPI pair was used to build a PPI network.

Cytoscape software [8] was used to define the topology of the built network, and the Molecular Complex Detection (MCODE) [9] was used to find densely connected region (modules) of the network that could be involved in the 
modulation of biological processes that are relevant for the disease pathogenesis. To find locally dense regions of a graph, MCODE applies a vertex-weighting scheme based on a clustering coefficient that is a measure of the degree to which nodes in a graph tend to cluster together.

The following settings in MCODE were used: degree cutoff $=2, \mathrm{~K}$-core $=3$, and max. depth $=100$. Functional enrichment for a given module was assessed quantitatively using the Panther tool.

2.5. Analysis of the Association between DEGs and Human Diseases. We used the software Ingenuity Pathway Analysis (IPA, Ingenuity Systems) to evaluate diseases and disorders that could be statistically significantly associated to gene modulation observed in NCGS samples. The statistical significance of gene-disease associations was calculated in IPA by the Fisher's exact test $(p \leq 0.0001)$.

2.6. Detection of Soluble Mediators in GS Sera. Serum levels of sCTLA-4, s PD-1, and sgp130/IL6ST were detected before and after gluten-free diet using commercially available ELISA kits according to the manufacturer's instructions. ELISA kits were purchased from Bender MedSystems (Milano, Italy) (sCTLA-4), from R\&D Systems (Minneapolis, United States) (sgp130), and from EMELCA Bioscience (Clinge, Netherlands) (sPD-1).

2.7. FACS Analysis. Cells collected from patients and normal controls were cultured at a concentration of $1^{*} 10^{6}$ cells $/ \mathrm{mL}$ in $2 \mathrm{~mL}$ tubes containing $1 \mathrm{~mL}$ of RPMI $1640+\mathrm{FCS} 10 \%$ (Lonza, Basel, CH). Cells were stimulated overnight with Dynabeads Human T-Activator CD3/CD28 (Life Technologies, Carlsbad, CA, USA). The detection of IL-17 production was analysed using the IL-17 Secretion Assay (Miltenyi Biotec, Bergisch Gladbach, D) following the manufacturer's instruction. Briefly, cells were washed with $2 \mathrm{~mL}$ of cold buffer at $300 \times \mathrm{g}$ for 5 minutes at $4^{\circ} \mathrm{C}$, and the pellet was resuspended in $90 \mu \mathrm{L}$ of cold medium. Cells were then incubated with $10 \mu \mathrm{L}$ of IL-17 Catch Reagent for 5 minutes in ice and cultured in $1 \mathrm{~mL}$ of warm medium at $37^{\circ} \mathrm{C}$ for 45 minutes under slow continuous rotation. Cells were then washed with cold buffer and resuspended in $75 \mu \mathrm{L}$ of cold buffer; $10 \mu \mathrm{L}$ of IL-17 Detection Antibody APC, $10 \mu \mathrm{L}$ of anti-CD3 PerCP (Becton Dickinson, Franklin Lakes, NJ, USA), and $5 \mu \mathrm{L}$ of anti-CD4 APC-H7 (Becton Dickinson) monoclonal antibodies were added. Incubation was carried out in ice for 10 minutes. Finally, cells were washed and resuspended in an appropriate volume of PBS and acquired on a FACSCanto II cytometer (Becton Dickinson). Analysis was performed with FlowJo 9.3.3 software (Tree Star, Ashland, OR, USA).

2.8. Statistical Analysis. Data obtained from the analysis of the soluble mediators CTLA-4, gp130, and PD-1 and from the detection of antigliadin antibodies were submitted to statistical testing using the Wilcoxon nonparametric statistical hypothesis test for paired samples.

Data obtained from the ELISA test for the detection of antirotavirus VP7 peptide antibodies were submitted to statistical testing using the Mann-Whitney nonparametric test. Statistical analysis was performed using GraphPad
Prism Software version 5.00 (GraphPad Software, La Jolla, California, USA, http://www.graphpad.com).

\section{Results and Discussion}

Many aspects of NCGS are still unknown; in particular, it is still not clear whether the disease is permanent or transient or whether the disease has features of autoimmunity. The pathogenesis of NCGS is also unclear and data obtained so far suggest a prevalent activation of innate immune responses [2].

We aimed at clarifying some aspects of NCGS pathogenesis using a gene array approach which we successfully used in the study of many immune-mediated diseases [6, 10-12].

In order to identify specific gene signatures typically associated with NCGS, we compared the gene expression profiles of 8 PBC samples obtained from individual NCGS patients with $10 \mathrm{PBC}$ samples obtained from healthy ageand sex-matched donors. We observed that the disease has a profound impact on gene expression profiles since a large number of differentially expressed genes (DEGs) (1293, represented by 1521 modulated probe sets) complied with the Bonferroni-corrected $p$ value criterion $(p \leq 0.01)$ and the fold change criterion $(F C \geq 1.5)$ showing robust and statistically significant variation between healthy controls and NCGS samples. In particular, 695 and 598 genes resulted to be upand downregulated, respectively (Additional Table 1).

DEGs were submitted to functional enrichment analysis according to terms of the Gene Ontology (GO) biological processes (BP) and canonical pathways. The most enriched biological process was "immune system" followed by "intracellular signal transduction" (Table 1). In addition, several enriched terms were related to the immune response gene category, including "leukocyte differentiation," "leukocyte activation involved in immune response," "T cell differentiation," "neutrophil degranulation," "adaptive immune response," and "defense response." Interestingly, we observed an enrichment in "cellular response to organic substance," "cellular response to endogenous stimulus," and "viral process." The BP named "viral process" is defined by the Gene Ontology Consortium as a "multi-organism process in which a virus is a participant and the other participant is the host." This term is related to the infection of a host cell, the replication of the viral genome, the viral transcription, and the assembly of progeny virus particles.

Pathway enrichment analysis showed that the most enriched signaling pathways were "inflammation mediated by chemokine and cytokine," "apoptosis," and "angiogenesis," followed by "T cell activation" and "B cell activation" (Table 1). Other enriched pathways were: "integrin signaling," "EGF receptor signaling," "Toll-like receptor signaling," "PI3 kinase," "interleukin signaling," and JAK/STAT signaling. Since the majority of the top-enriched functional classes and pathways were related to the immune system, we selected, within the entire data set, all modulated genes associated to the "Immune response" GO term to better characterize the immunological processes that are involved in NCGS pathogenesis. Although both innate and adaptive immunity play a crucial role in the development of $\mathrm{CD}$, 
TABLE 1: Biological processes and pathways that were enriched in the NCGS dataset.

\begin{tabular}{|c|c|}
\hline Biological processes & p value* \\
\hline Immune system process & $6.3 \times 10^{-26}$ \\
\hline Intracellular signal transduction & $4.6 \times 10^{-16}$ \\
\hline Cellular response to organic substance & $1.5 \times 10^{-13}$ \\
\hline Cell surface receptor signaling pathway & $8.2 \times 10^{-10}$ \\
\hline Leukocyte differentiation & $6.3 \times 10^{-9}$ \\
\hline Viral process & $7.7 \times 10^{-9}$ \\
\hline Leukocyte activation involved in immune response & $8.0 \times 10^{-8}$ \\
\hline Apoptotic process & $2.2 \times 10^{-6}$ \\
\hline Cellular response to endogenous stimulus & $3.0 \times 10^{-6}$ \\
\hline $\mathrm{T}$ cell differentiation & $5.6 \times 10^{-5}$ \\
\hline Neutrophil degranulation & $5.6 \times 10^{-5}$ \\
\hline Adaptive immune response & $6.5 \times 10^{-5}$ \\
\hline Defense response & $6.8 \times 10^{-5}$ \\
\hline Pathways & p value* \\
\hline $\begin{array}{l}\text { Inflammation mediated by chemokine and cytokine } \\
\text { signaling pathway }\end{array}$ & $2.1 \times 10^{-7}$ \\
\hline Apoptosis signaling pathway & $1.6 \times 10^{-4}$ \\
\hline Angiogenesis & $4.1 \times 10^{-4}$ \\
\hline T cell activation & $5.3 \times 10^{-4}$ \\
\hline B cell activation & $5.7 \times 10^{-4}$ \\
\hline Integrin signaling pathway & $7.8 \times 10^{-4}$ \\
\hline EGF receptor signaling pathway & $4.0 \times 10^{-3}$ \\
\hline Toll like receptor signaling pathway & $4.6 \times 10^{-3}$ \\
\hline PI3 kinase pathway & $7.6 \times 10^{-3}$ \\
\hline Interleukin signaling pathway & $8.1 \times 10^{-3}$ \\
\hline JAK/STAT signaling pathway & $1.6 \times 10^{-2}$ \\
\hline
\end{tabular}

*Bonferroni corrected.

NCGS has been mainly associated with activation of the innate immune response [2].

It is therefore surprising to notice that both transcripts involved in the innate immune response as well as genes of the adaptive immune response were well represented in our dataset (Table 2).

In this regard, 14 genes involved in NK activity were modulated in NCGS samples (i.e., LILRA1, LILRA2, CLEC2D, and KLRC4). Moreover, several genes involved in macrophage activation were modulated in NCGS including TNFRSF10B, the ligand of the death receptors TRAIL that play important roles in set up both innate and adaptive immune responses against pathogens [13], and the scavenger receptors MRC1/CD206 [14] and MARCO, a member of the class A scavenger receptor family strongly upregulated in $\mathrm{M} \Phi$ by various microbial stimuli in a TLR-dependent manner [15].

Noteworthy, 38 genes prevalently related to B cell activity (i.e., IL2RG, IL6R, KLF12, and CD27) were also modulated, indicating an important role for this cell subset in NCGS, 20 genes involved in $\mathrm{T}$ cell activation were upregulated in
NCGS samples (i.e., CD28, CD3E, CD3G, and CTLA-4). Remarkably, Th17-lymphocyte-related genes and transcripts that can modulate Th17 cell development and functions were overexpressed including IL4R, IL2RG, IL6ST, IL1B, IL7R, STAT6, STAT5B, SOCS3, and CXCL2.

DEGs indicate therefore active involvement of both arms of the adaptive immune response (i.e., $\mathrm{T}$ and $\mathrm{B}$ cells response) and a prevalent upregulation of several Th17-related genes in the $\mathrm{T}$ cell response category. It is well known that Th17 cells play an important role in autoimmunity and have been implicated in the pathogenesis of psoriasis and in the amplification of inflammation in rheumatoid synovitis and in lupus nephritis [16-18].

In the NCGS dataset, 6 type I interferon inducible genes (IFIG) were upregulated (IFNA17, IRF5, IRF3, STAT2, STAT1, and LY9), thus indicating the presence of an IFN type I signature, typically associated with autoimmune disease such as systemic lupus erythematosus (SLE), rheumatoid arthritis (RA), Crohn's disease, and Sjogren syndrome [19-25].

In this respect, it is well known that Th17 cells and related cytokines are crucial in promoting autoimmunity, in particular, when they act in synergy with type I IFN-driven inflammation. In the presence of IFN type I signature, CCR6 ${ }^{+}$ memory T-helper cells producing IL-17A, IL-17F, IL-21, and/or IL-22 are increased in SLE, [26] indicating that, in the pathogenesis of systemic autoimmune diseases, IFN type I signature coacts with Th17 cells and related cytokines.

In order to further confirm our gene expression data on overexpression of IFIG and Th17 pathways, we analysed the presence of IL-17-producing CD4+ T cells and found a significantly ( $p=0.0159)$ increased percentage of these cells in PBMC of patients with NCGS compared with normal subjects (Figure 1).

The analysis of genes modulated in gluten sensitivity was paralleled by the detection of some of the corresponding soluble mediators in the sera of NCGS patients. We analysed selected molecules that are widely recognized to be associated to an autoimmune response, including sCTLA-4, sPD-1, and sgp130/IL6ST. Figure 2 shows the concentration of these molecules in the sera of NCGS patients before and after gluten-free diet. The serum levels of all the molecules tested were significantly higher in NCGS before GFD than after GFD.

In order to gain further insights into the molecular mechanisms relevant in NCGS pathogenesis, we constructed a protein-protein interaction (PPI) network starting from all the 1293 DEGs. The resulted PPI network contained 853 nodes and 3512 edges (Figure 3). By performing a modular analysis of the constructed PPI network, we were able to identify clusters of the most densely interconnected nodes (modules) and to extrapolate 15 main modules of genes displaying the highest degree of connection. Figure 4 shows a graphical representation of such modules, where the nodes represent proteins and the edges indicate their relations.

All modules were submitted to enrichment analysis to find enriched GO biological processes and pathways.

Among the 15 modules in particular, five (module 1, 3, 7, 10, and 14) showed a prevalent enrichment in BP and 


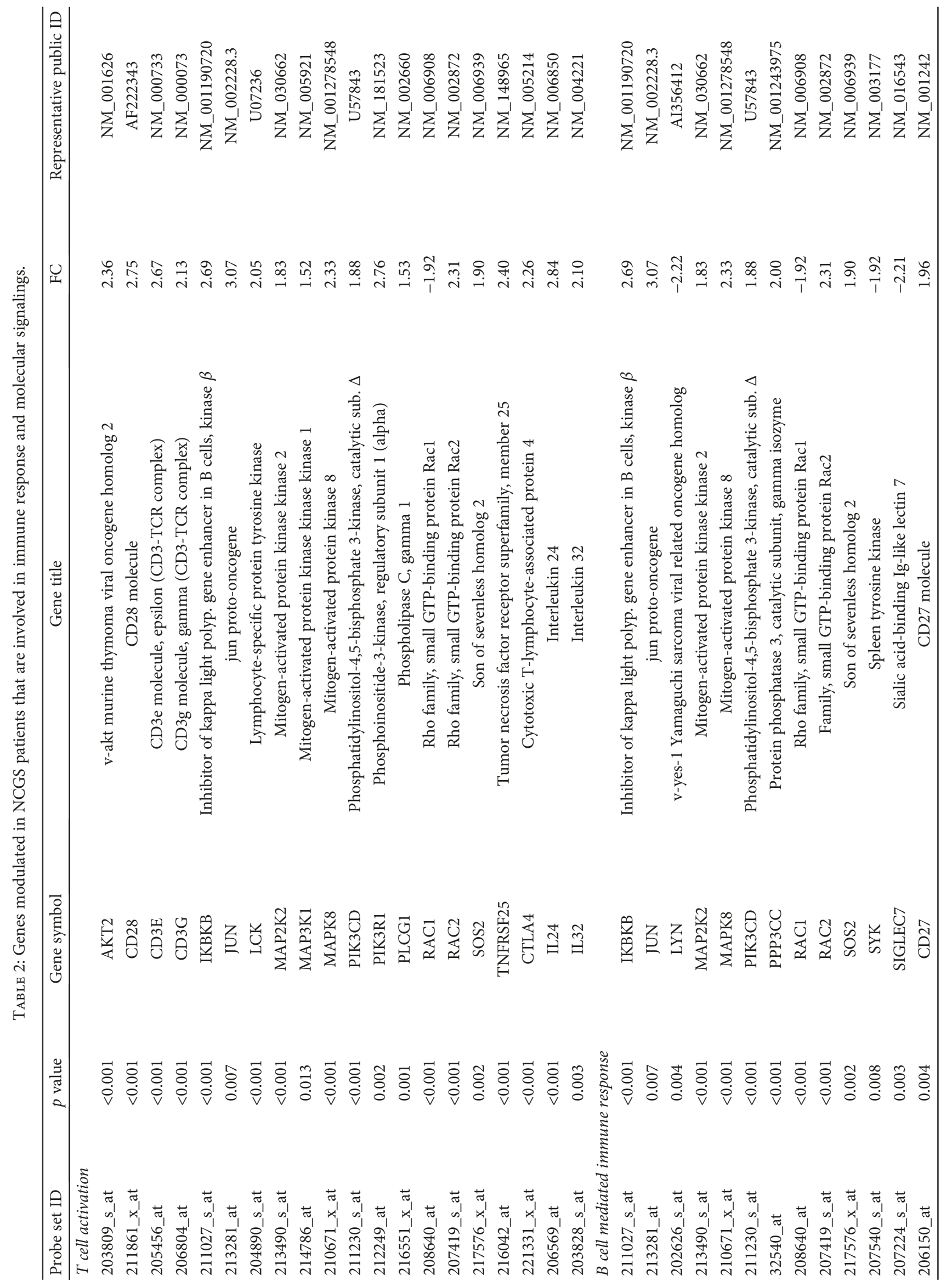




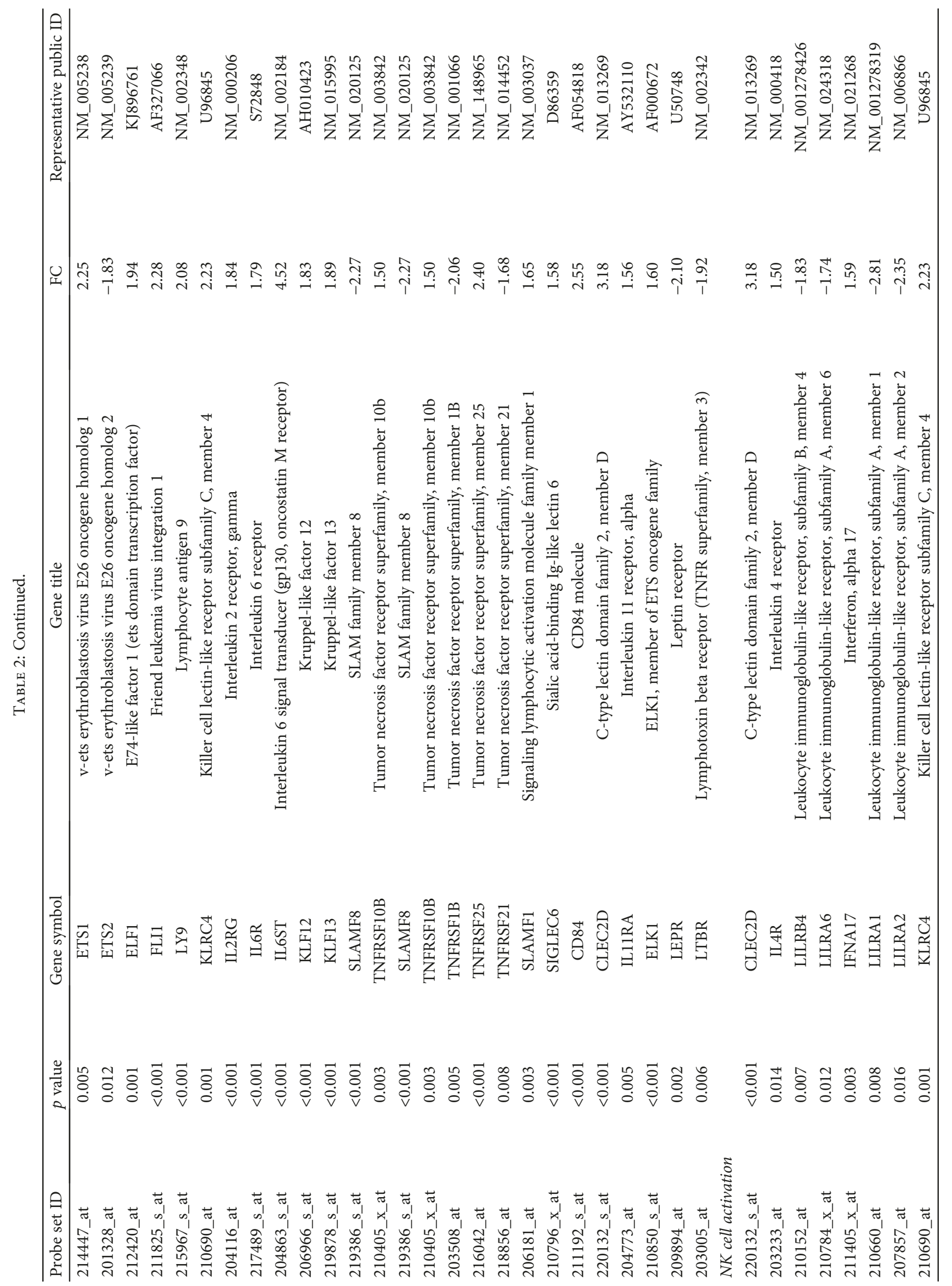




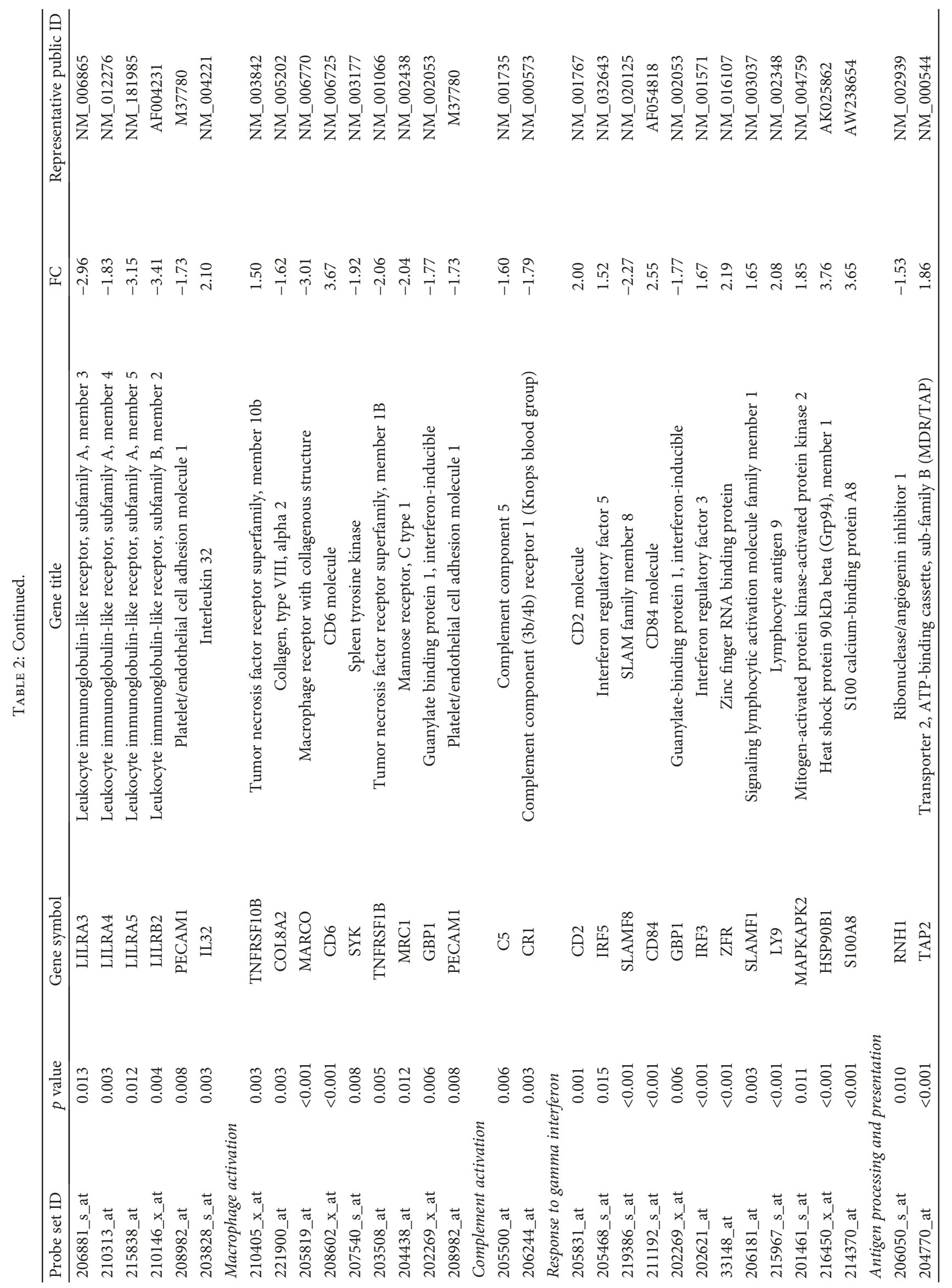




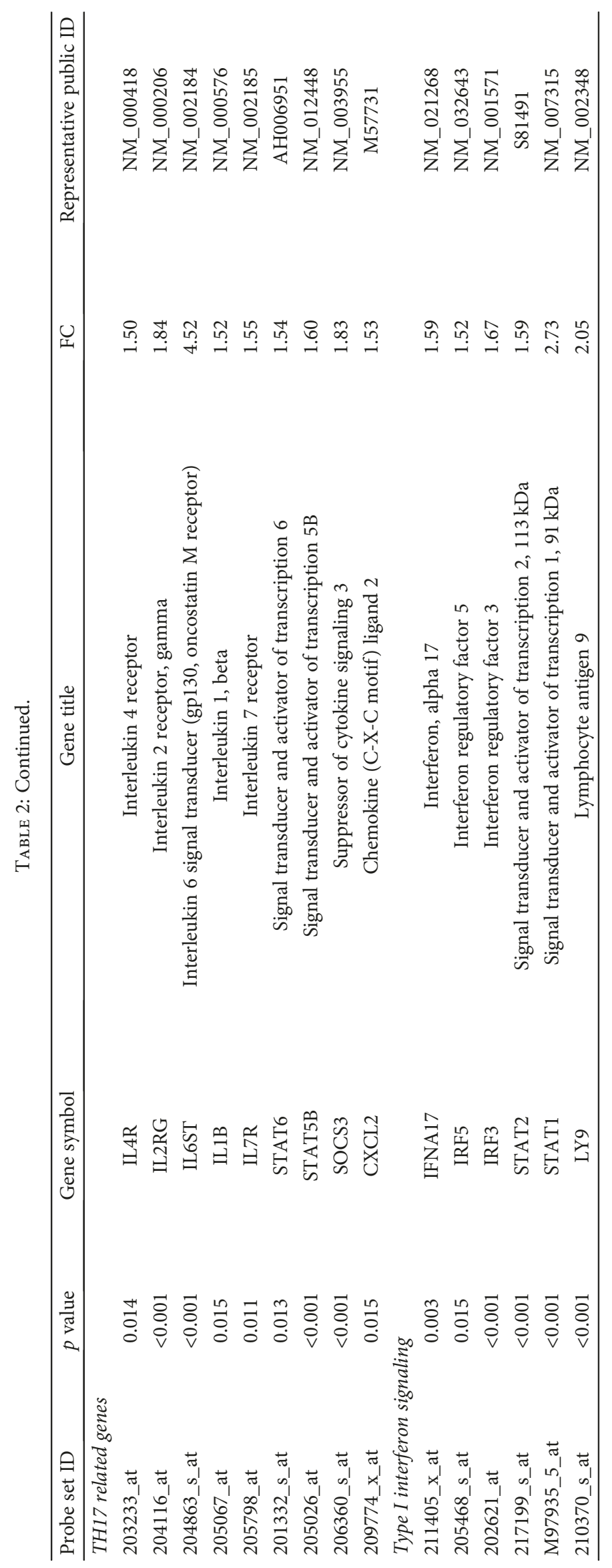




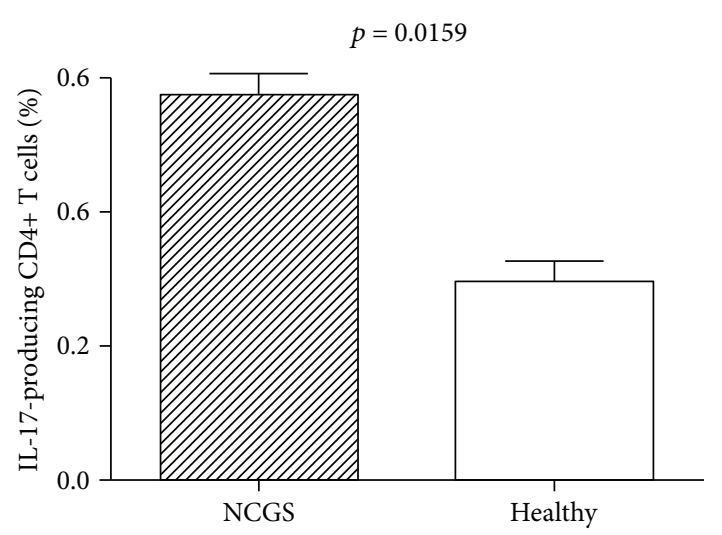

Figure 1: Flow cytometric analysis of CD4+T cells releasing IL-17 in patients with NCGS. Panel displays the mean percentage of CD4+T cells releasing IL-17 of 10 healthy donors and 8 NCGS patients. PBMCs were stimulated overnight with anti-CD3/CD28-coated beads. $p$ value calculated with the Mann-Whitney nonparametric statistical test was 0.0159 .

pathways associated to the activation of T cells. Similarly, "B cell activation" pathways were significantly enriched in modules $1,9,10$, and 14. Interestingly, in modules 3,10 , and 11 , we observed an enrichment in the JAK-STAT signaling pathway, which is highly relevant to human autoimmunity [27] and plays a role in the intestinal mucosal immune homeostasis as well as in intestinal epithelial repair and regeneration [28]. We also observed that module 11 contained several genes involved in Th-17 cell functions (i.e., IL2RG, IL4R, IL6ST, IL7R, SOCS3, STAT5B, and STAT6) and several IFIG, including IFNA17, STAT1, and STAT2. Other IFIG genes were ascribed to module 9 which also shows an enrichment in BPs associated to type I interferon signaling, including positive regulation of type I interferon production, positive regulation of interferon-beta production, and type I interferon biosynthetic process (Table 3).

Loss of the intestinal barrier integrity is a typical feature of $\mathrm{CD}$ and represents an important mechanism of autoimmunization through the passage of antigens across the intestinal epithelium [29]. However, Sapone et al. [29] have shown that NCGS patients have normal intestinal permeability when compared to $\mathrm{CD}$ patients, as assessed by the lactulose-mannitol test.

Indeed, in module 13, in which the most enriched BP was "adherent junction assembly," we observed a reduced expression of molecules involved in cell adhesion including CDH1 (epithelial cadherin), CTNNA1, VCL, and CTTN, a molecule expressed on the apical surface of the polarized epithelium. In the same module, we also observed underexpression of Rac1, a critical regulator of intestinal epithelial barrier functions [30] and EGF, known to protect intestinal barrier integrity by stabilizing the microtubule cytoskeleton [31] and upregulation of FYN and PIK3R1, both involved in the signaling pathway by which IFN $\gamma$ increases intestinal permeability [32].

The gene expression data would therefore indicate deregulation of adherent junctions and altered intestinal permeability also in NCGS, which seems to be in contrast with the data of Sapone et al. Nevertheless, it is important to point out that the lactulose-mannitol test may not be sensitive enough to detect mild alterations of the intestinal barrier function in patients with NCGS.

In module 12, the most enriched pathway was "inflammation mediated by chemokine and cytokine signaling"; this pathway was also enriched in modules 9,10 , and 11 , which is consistent with inflammatory/autoimmune origin of NCGS.

Moreover, modules 1, 2, 7, and 10 were enriched in BPs related to viral infection including "viral process," "viral gene expression," "intracellular transport of virus," and "regulation of defense response to virus."

In addition, we observed that modules 10 and 11 showed enrichments in the gamma interferon pathways typically associated to the innate response to viruses [33].

Therefore, to further clarify the relationship between viral infections and NCGS, we searched in the IPA software database to find all diseases that are most likely to be statistically significantly associated to the genes modulated in the NCGS dataset. We found that, in the resulting list of most significantly associated diseases, "Infectious diseases" ranked first and, among these, "Viral infection" showed the best statistical $p$ value (Figure 5(a)). Moreover, we could find a cluster of 134 DEGs that, in our NCGS dataset, showed a modulation that was consistent with a process of viral infection (Figure 5(b)). Based on these data, we aimed at investigating whether rotavirus, known to be linked to $\mathrm{CD},[5,6$, $34]$ could also play a role in NCGS.

In the second part of our study, we made a comparison between the dataset obtained from our previous analysis of intestinal human T84 cells treated with anti-VP7 antibodies (that we indicate in this paper as "T84 dataset") and genes modulated in NCGS. We found that 529 genes modulated in NCGS (accounting for the $41 \%$ of genes modulated in this dataset) were also modulated in treated T84 cells. Interestingly, several DEGs that were shared by the two datasets are involved in BP that may be related to the pathogenesis of celiac disease, including apoptosis, inflammatory and immune response, cell proliferation, cell differentiation, cell junctions, matrix metalloproteases, receptors and signal transducers, cytoskeleton components, ion transport and exchange, and EGF receptor pathway. Table 4 shows a selection of genes ascribed to the abovementioned functional classes. As a whole in NCGS dataset, the modulation of genes ascribed to the abovementioned categories indicated an upregulation of apoptotic genes accompanied by a downregulation of genes involved in cell differentiation and an increased transcription of proliferative genes. All these observation are in agreement with what we described on human T84 cells treated with antirotavirus $\mathrm{Vp} 7$ peptide antibodies and are related to the typical features of celiac disease. Indeed in $\mathrm{CD}$, an increased apoptosis is the main cause of villous atrophy that is also sustained by a dysregulation of cell differentiation [35]. Moreover, it has been observed that the increase of intestinal cell proliferation leads to crypt hyperplasia seen in celiac disease [35]. Other aspects of CD previously observed in our T84 treated cells, that are paralleled by the 


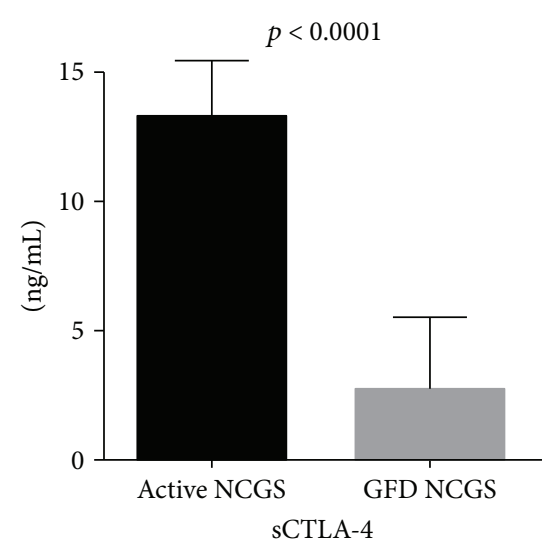

(a)

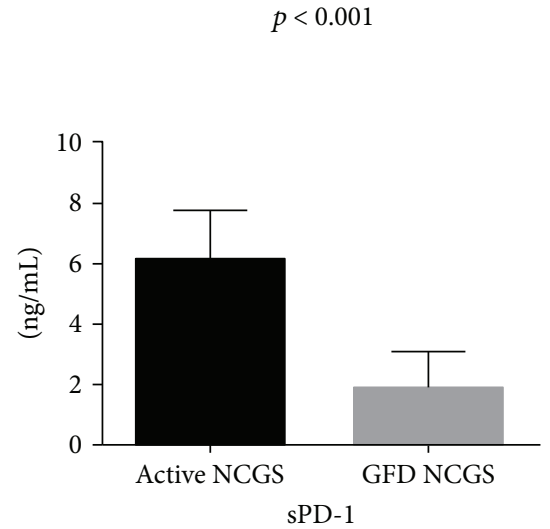

(b) $p<0.05$

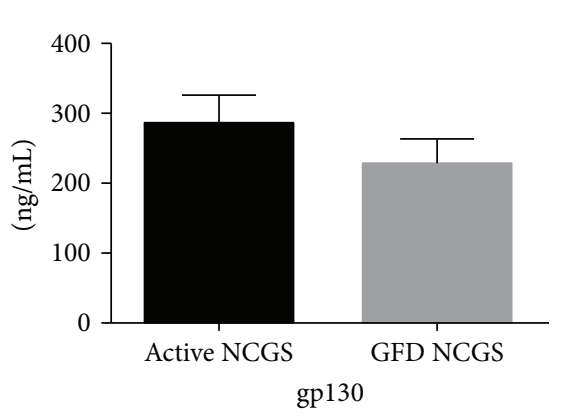

(c)

FIGURE 2: Serum levels of selected soluble mediators in NCGS patients and in normal subject sera. The histograms represent the mean of the results obtained in 20 healthy donors and in 16 NCGS patients. $p$ values calculated with the Wilcoxon nonparametric statistical test for paired samples were: $p<0.0001$ for sCTLA- $4, p<0.001$ for sPD-1, and $p<0.05$ for sgp 130 .

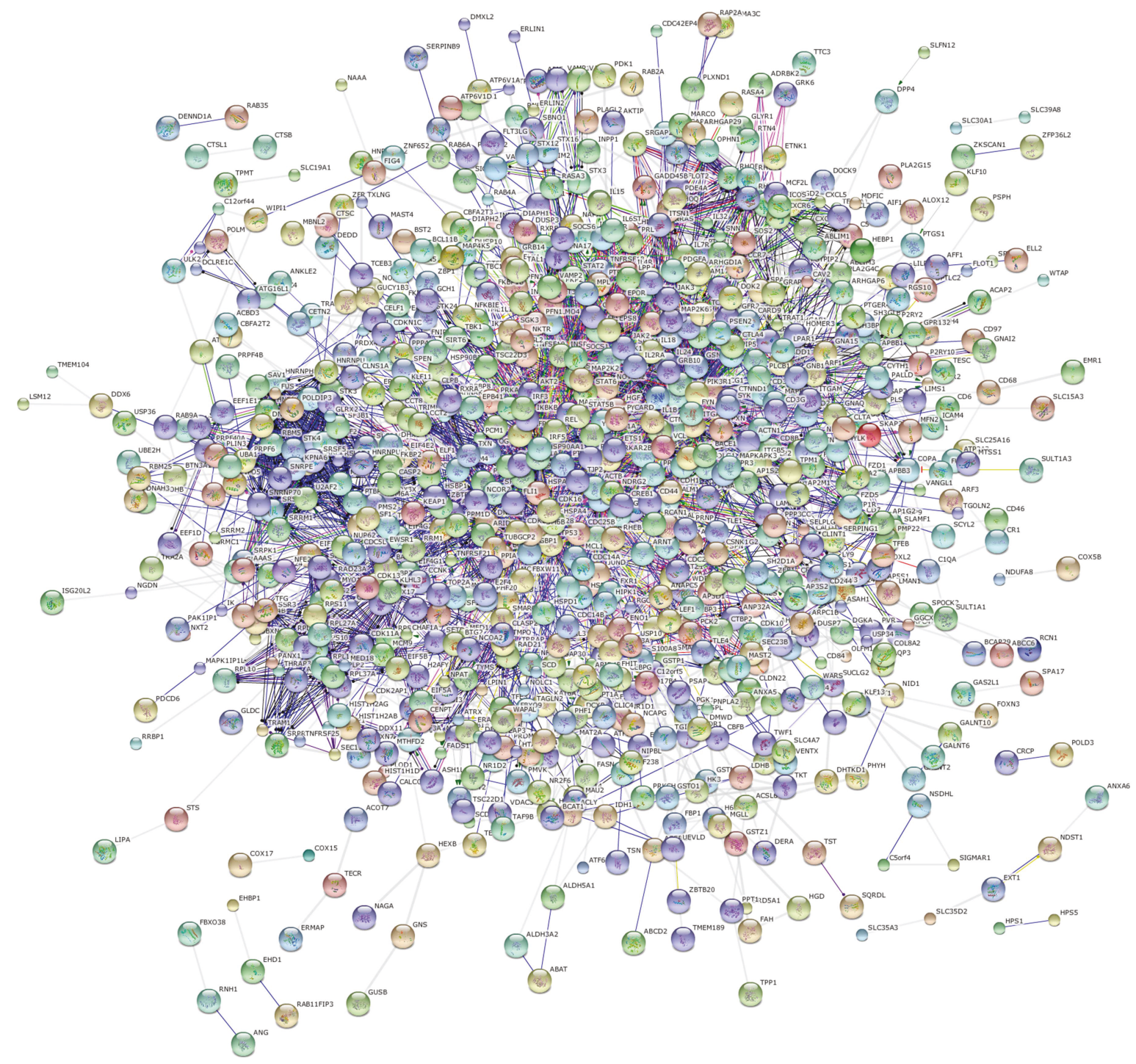

FIGURE 3: Protein-protein interaction (PPI) network of DEGs in NCGS patients. 
M0

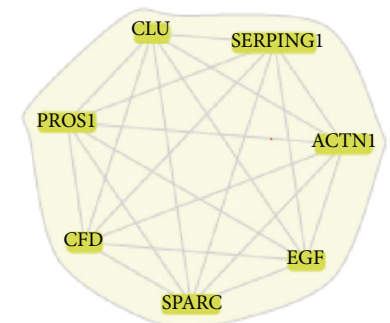

M3

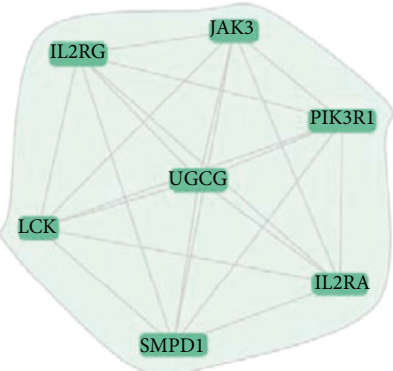

M6

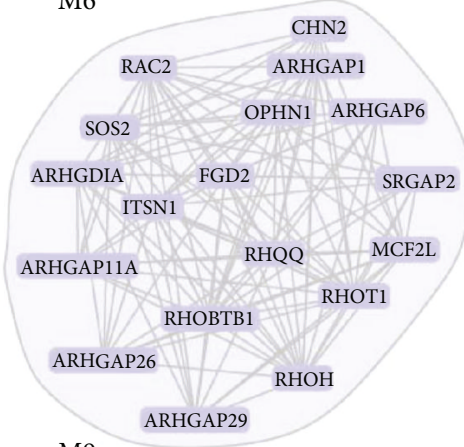

M9

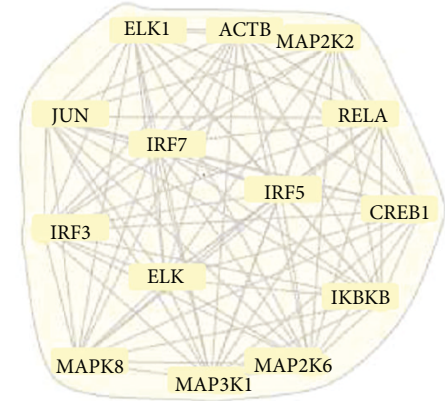

M12

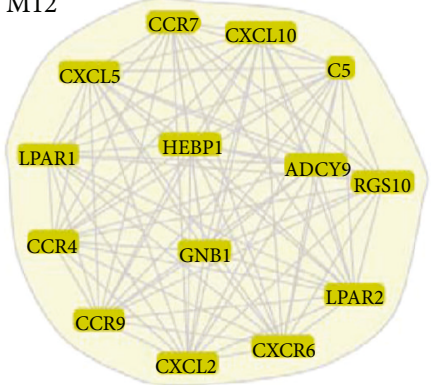

M1

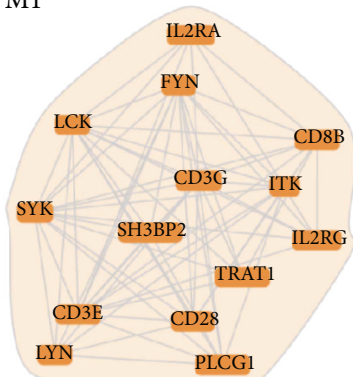

M4

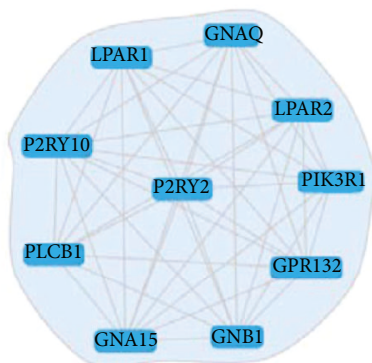

M7

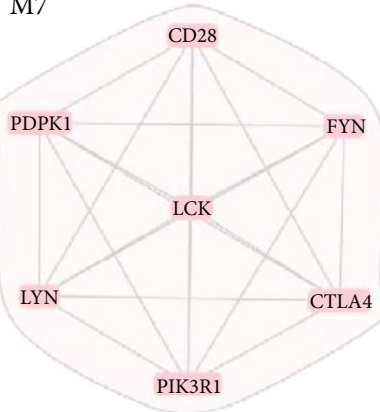

M10

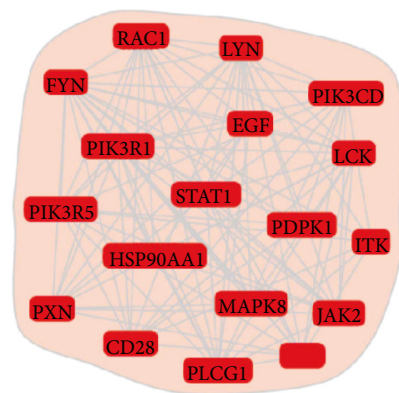

M13

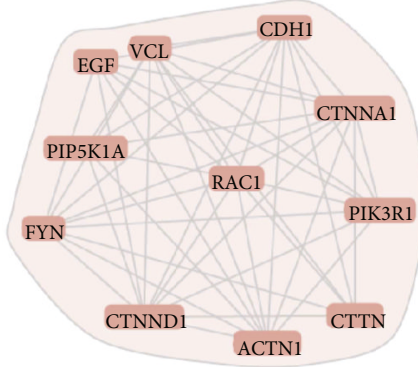

M2
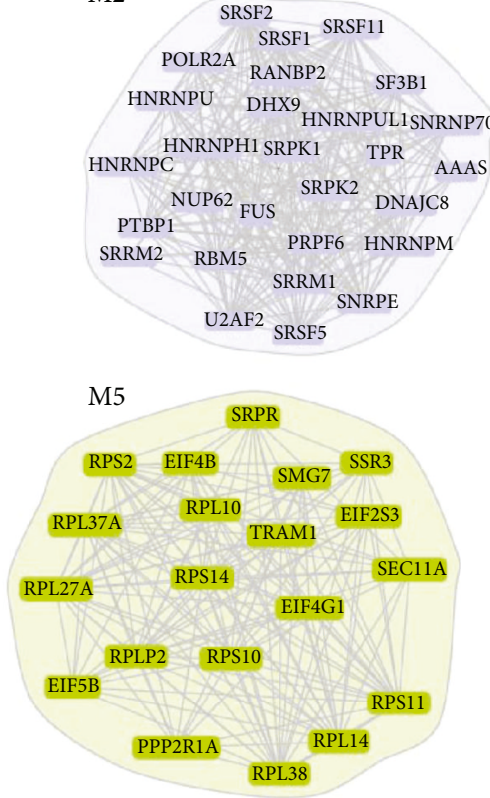

M8

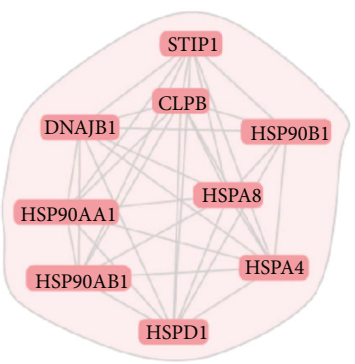

M11

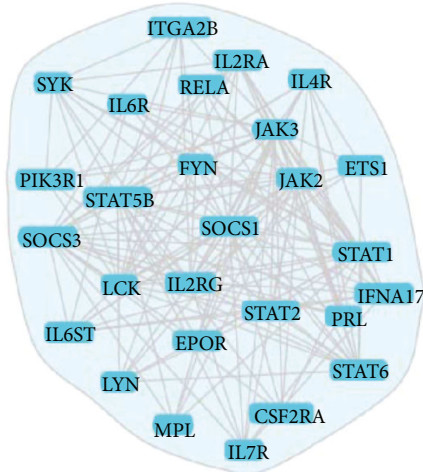

M14

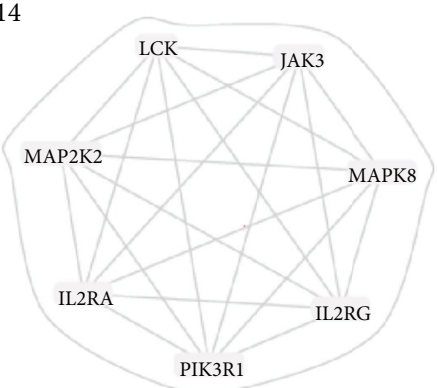

FIGURE 4: Modules originated from the network analysis of DEGs in NCGS patients. 
TABLE 3: Biological processes and pathways enriched in the 15 modules.

\begin{tabular}{|c|c|c|c|}
\hline Biological processes & $\begin{array}{c}p \\
\text { value }\end{array}$ & Pathways & $\begin{array}{c}p \\
\text { value }\end{array}$ \\
\hline \multicolumn{4}{|l|}{ MO } \\
\hline Exocytosis & $<0.001$ & None & \\
\hline Secretion by cell & $<0.001$ & & \\
\hline Secretion & $<0.001$ & & \\
\hline Vesicle-mediated transport & 0.0018 & & \\
\hline Single-organism transport & 0.0220 & & \\
\hline Single-organism localization & 0.0308 & & \\
\hline \multicolumn{4}{|l|}{ M1 } \\
\hline $\mathrm{T}$ cell receptor signaling pathway & $<0.001$ & $\mathrm{~T}$ cell activation & $<0.001$ \\
\hline $\begin{array}{l}\text { Transmembrane receptor protein tyrosine kinase } \\
\text { signaling pathway }\end{array}$ & $<0.001$ & B cell activation & 0.0012 \\
\hline $\mathrm{T}$ cell costimulation & $<0.001$ & Cadherin signaling pathway & 0.0056 \\
\hline Viral process & $<0.001$ & Integrin signaling pathway & 0.0081 \\
\hline $\begin{array}{l}\text { Fc-gamma receptor signaling pathway involved in } \\
\text { phagocytosis }\end{array}$ & $<0.001$ & & \\
\hline Peptidyl-tyrosine modification & 0.0016 & & \\
\hline Adaptive immune response & 0.0017 & & \\
\hline $\begin{array}{l}\text { Positive regulation of antigen receptor-mediated } \\
\text { signaling pathway }\end{array}$ & 0.0029 & & \\
\hline Positive regulation of alpha-beta $\mathrm{T}$ cell proliferation & 0.0038 & & \\
\hline Phosphatidylinositol phosphorylation & 0.0060 & & \\
\hline Phosphatidylinositol-mediated signaling & 0.0162 & & \\
\hline Positive regulation of calcium-mediated signaling & 0.0192 & & \\
\hline T cell selection & 0.0244 & & \\
\hline Leukocyte migration & 0.0303 & & \\
\hline Interleukin-2-mediated signaling pathway & 0.0324 & & \\
\hline MAPK cascade & 0.0371 & & \\
\hline Positive regulation of immune effector process & 0.0466 & & \\
\hline Positive regulation of defense response & 0.0485 & & \\
\hline \multicolumn{4}{|l|}{ M2 } \\
\hline mRNA export from nucleus & $<0.001$ & None & \\
\hline Spliceosomal complex assembly & $<0.001$ & & \\
\hline Termination of RNA polymerase II transcription & $<0.001$ & & \\
\hline Regulation of mRNA splicing, via spliceosome & $<0.001$ & & \\
\hline Positive regulation of RNA splicing & $<0.001$ & & \\
\hline mRNA 3 '-end processing & $<0.001$ & & \\
\hline Regulation of gene silencing by miRNA & $<0.001$ & & \\
\hline tRNA export from nucleus & 0.0010 & & \\
\hline Viral gene expression & 0.0054 & & \\
\hline Intracellular transport of virus & 0.0078 & & \\
\hline Protein sumoylation & 0.0294 & & \\
\hline Regulation of cellular response to heat & 0.0310 & & \\
\hline Fibroblast growth factor receptor signaling pathway & 0.0414 & & \\
\hline \multicolumn{4}{|l|}{ M3 } \\
\hline Positive regulation of $\mathrm{T}$ cell activation & 0.0035 & $\mathrm{~T}$ cell activation & $<0.001$ \\
\hline Interleukin-2-mediated signaling pathway & 0.0065 & Interleukin signaling pathway & $<0.001$ \\
\hline Interleukin-4-mediated signaling pathway & 0.0065 & PDGF signaling pathway & 0.0010 \\
\hline Protein phosphorylation & 0.0349 & Integrin signaling pathway & 0.0017 \\
\hline
\end{tabular}


TABle 3: Continued.

\begin{tabular}{|c|c|c|c|}
\hline Biological processes & $\begin{array}{c}p \\
\text { value }\end{array}$ & Pathways & $\begin{array}{c}p \\
\text { value }\end{array}$ \\
\hline & & JAK/STAT signaling pathway & 0.0057 \\
\hline & & Hypoxia response via HIF activation & 0.0110 \\
\hline & & Insulin/IGF pathway-protein kinase B signaling cascade & 0.0136 \\
\hline & & p53 pathway feedback loops 2 & 0.0176 \\
\hline & & PI3 kinase pathway & 0.0182 \\
\hline & & VEGF signaling pathway & 0.0238 \\
\hline & & Endothelin signaling pathway & 0.0284 \\
\hline & & p53 pathway & 0.0290 \\
\hline
\end{tabular}

M4

Pospholipase C-activating G-protein-coupled receptor signaling pathway

G-protein coupled acetylcholine receptor signaling pathway

Activation of phospholipase $\mathrm{C}$ activity

Positive regulation of cytosolic calcium ion concentration

Adenylate cyclase-modulating G-protein-coupled receptor signaling pathway

M5

Translational initiation

Nuclear-transcribed mRNA catabolic process, nonsense mediated decay

SRP-dependent cotranslational protein targeting to membrane

rRNA processing

Ribosomal small subunit assembly

M6

Regulation of small GTPase-mediated signal transduction

Positive regulation of GTPase activity

Small GTPase-mediated signal transduction

Actin cytoskeleton organization

M7

$\mathrm{T}$ cell costimulation

Phosphatidylinositol-mediated signaling

$\mathrm{T}$ cell receptor signaling pathway

Phosphatidylinositol phosphorylation

Transmembrane receptor protein tyrosine kinase signaling pathway

Peptidyl-tyrosine autophosphorylation

$<0.001$

$<0.001$

$<0.001$

$<0.001$

$<0.001$

$<0.001$

0.0048

$<0.001$

$<0.001$

$<0.001$

0.0083

$<0.001$

$<0.001$

$<0.001$

0.0108

$<0.001$

$<0.001$

$<0.001$

0.0016

0.0033

0.0035

0.0050

0.0055

0.0122

0.0232

0.0237

0.0256

0.0340
Heterotrimeric G-protein signal. pathway-Gq $\alpha$ and Go $\alpha$ med. pathway

$<0.001$

0.0013

Endothelin signaling pathway

0.0015

None

None

$\mathrm{T}$ cell activation

$<0.001$

Integrin signaling pathway

0.0041

$$
\text { Wnt signaling pathway }
$$

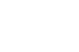

B cell receptor signaling pathway

Positive regulation of defense response 
TABle 3: Continued.

\begin{tabular}{|c|c|c|c|}
\hline Biological processes & $\begin{array}{c}p \\
\text { value }\end{array}$ & Pathways & $\begin{array}{c}p \\
\text { value }\end{array}$ \\
\hline \multicolumn{4}{|l|}{ M8 } \\
\hline Response to unfolded protein & $<0.001$ & None & \\
\hline Response to topologically incorrect protein & $<0.001$ & & \\
\hline Chaperone-mediated protein complex assembly & $<0.001$ & & \\
\hline Protein folding & $<0.001$ & & \\
\hline Protein transmembrane transport & $<0.001$ & & \\
\hline Response to stress & $<0.001$ & & \\
\hline \multicolumn{4}{|l|}{ M9 } \\
\hline Activation of innate immune response & $<0.001$ & Toll-like receptor signaling pathway & $<0.001$ \\
\hline Positive regulation of innate immune response & $<0.001$ & Ras pathway & $<0.001$ \\
\hline Toll-like receptor signaling pathway & $<0.001$ & Apoptosis signaling pathway & $<0.001$ \\
\hline Fc-epsilon receptor signaling pathway & 0.0020 & $\mathrm{~T}$ cell activation & $<0.001$ \\
\hline MAPK cascade & 0.0026 & p38 MAPK pathway & $<0.001$ \\
\hline Positive regulation of type I interferon production & 0.0029 & Oxidative stress response & $<0.001$ \\
\hline Positive regulation of cytokine production & 0.0035 & Angiogenesis & $<0.001$ \\
\hline TRIF-dependent toll-like receptor signaling pathway & 0.0136 & B cell activation & $<0.001$ \\
\hline Positive regulation of interferon-beta production & 0.0202 & FGF signaling pathway & $<0.001$ \\
\hline Response to lipopolysaccharide & 0.0268 & EGF receptor signaling pathway & $<0.001$ \\
\hline \multirow[t]{3}{*}{ Type I interferon biosynthetic process } & 0.0419 & Integrin signaling pathway & 0.0024 \\
\hline & & $\begin{array}{l}\text { Inflammation mediated by chemokine and cytokine signaling } \\
\text { pathway }\end{array}$ & 0.0079 \\
\hline & & Interleukin signaling pathway & 0.0104 \\
\hline \multicolumn{4}{|l|}{ M10 } \\
\hline $\mathrm{T}$ cell receptor signaling pathway & $<0.001$ & $\mathrm{~T}$ cell activation & $<0.001$ \\
\hline T cell costimulation & $<0.001$ & EGF receptor signaling pathway & $<0.001$ \\
\hline Fc-epsilon receptor signaling pathway & $<0.001$ & Integrin signaling pathway & $<0.001$ \\
\hline phosphatidylinositol phosphorylation & $<0.001$ & p53 pathway feedback loops 2 & $<0.001$ \\
\hline Peptidyl-tyrosine autophosphorylation & $<0.001$ & VEGF signaling pathway & $<0.001$ \\
\hline $\begin{array}{l}\text { Fc-gamma receptor signaling pathway involved in } \\
\text { phagocytosis }\end{array}$ & $<0.001$ & B cell activation & $<0.001$ \\
\hline Leukocyte migration & $<0.001$ & Ras pathway & $<0.001$ \\
\hline Growth hormone receptor signaling pathway & $<0.001$ & Angiogenesis & $<0.001$ \\
\hline Regulation of defense response to virus & $<0.001$ & \multirow{2}{*}{ Insulin/IGF pathway-protein kinase B signaling cascade } & \multirow[t]{2}{*}{$<0.001$} \\
\hline Innate immune response & $<0.001$ & & \\
\hline Positive regulation of MAP kinase activity & $<0.001$ & \multirow{2}{*}{$\begin{array}{l}\text { Inflammation mediated by chemokine and cytokine signaling } \\
\text { pathway }\end{array}$} & \multirow[t]{2}{*}{$<0.001$} \\
\hline T cell differentiation & $<0.001$ & & \\
\hline Regulation of apoptotic process & $<0.001$ & PI3 kinase pathway & $<0.001$ \\
\hline JAK-STAT cascade & 0.0011 & p53 pathway & $<0.001$ \\
\hline Positive regulation of immune effector process & 0.0031 & Interferon-gamma signaling pathway & $<0.001$ \\
\hline MAPK cascade & 0.0056 & FGF signaling pathway & $<0.001$ \\
\hline Adaptive immune response & 0.0088 & Endothelin signaling pathway & 0.0101 \\
\hline B cell receptor signaling pathway & 0.0121 & JAK/STAT signaling pathway & 0.0176 \\
\hline Phosphatidylinositol 3-kinase signaling & 0.0214 & & \\
\hline Stimulatory C-type lectin receptor signaling pathway & 0.0363 & & \\
\hline $\begin{array}{l}\text { Innate immune response activ. cell surface receptor } \\
\text { signal. pathway }\end{array}$ & 0.0387 & & \\
\hline
\end{tabular}


TABle 3: Continued.

\begin{tabular}{|c|c|c|c|}
\hline Biological processes & $\begin{array}{c}p \\
\text { value }\end{array}$ & Pathways & $\begin{array}{c}p \\
\text { value }\end{array}$ \\
\hline \multicolumn{4}{|l|}{ M11 } \\
\hline Cellular response to cytokine stimulus & $<0.001$ & JAK/STAT signaling pathway & $<0.001$ \\
\hline $\begin{array}{l}\text { JAK-STAT cascade involved in growth hormone } \\
\text { signaling pathway }\end{array}$ & $<0.001$ & Interleukin signaling pathway & $<0.001$ \\
\hline Positive regulation of cytokine production & $<0.001$ & PDGF signaling pathway & $<0.001$ \\
\hline Response to interleukin-2 & $<0.001$ & Interferon-gamma signaling pathway & $<0.001$ \\
\hline Positive regulation of $\mathrm{T}$ cell differentiation & $<0.001$ & EGF receptor signaling pathway & $<0.001$ \\
\hline $\begin{array}{l}\text { Positive regulation of tyrosine phosphorylation of STAT } \\
\text { protein }\end{array}$ & $<0.001$ & Integrin signaling pathway & $<0.001$ \\
\hline $\begin{array}{l}\text { Regulation of interferon-gamma-mediated signaling } \\
\text { pathway }\end{array}$ & $<0.001$ & $\begin{array}{l}\text { Inflammation mediated by chemokine and cytokine signaling } \\
\text { pathway }\end{array}$ & $<0.001$ \\
\hline MAPK cascade & $<0.001$ & & \\
\hline Adaptive immune response & $<0.001$ & p53 pathway feedback loops 2 & 0.0025 \\
\hline Innate immune response & 0.0014 & PI3 kinase pathway & 0.0027 \\
\hline Positive regulation of $\mathrm{T}$ cell proliferation & 0.0022 & VEGF signaling pathway & 0.0045 \\
\hline Positive regulation of inflammatory response & 0.0025 & B cell activation & 0.0045 \\
\hline Antigen receptor-mediated signaling pathway & 0.0072 & Ras pathway & 0.0050 \\
\hline T cell differentiation & 0.0085 & T cell activation & 0.0078 \\
\hline Inflammatory response & 0.0194 & Cadherin signaling pathway & 0.0201 \\
\hline $\begin{array}{l}\text { Positive regulation of antigen receptor-mediated } \\
\text { signaling pathway }\end{array}$ & 0.0227 & & \\
\hline Transcription factor import into nucleus & 0.0313 & & \\
\hline T cell costimulation & 0.0396 & & \\
\hline M12 & & Inflammation mediated by chemokine and cytokine signaling & $<0.001$ \\
\hline G-protein-coupled receptor signaling pathway & $<0.001$ & pathway & \\
\hline Chemokine-mediated signaling pathway & $<0.001$ & Heterotrimeric G-protein signaling pathway-Gi alpha and Gs & 0.0473 \\
\hline $\begin{array}{l}\text { Positive regulation of cytosolic calcium ion } \\
\text { concentration }\end{array}$ & $<0.001$ & $\begin{array}{l}\text { Heterotrimeric G-protein signaling pathway-Gl alpha and Gs } \\
\text { alpha-mediated pathway }\end{array}$ & \\
\hline Inflammatory response & $<0.001$ & & \\
\hline Cell chemotaxis & $<0.001$ & & \\
\hline Positive regulation of neutrophil chemotaxis & 0.0136 & & \\
\hline Response to lipopolysaccharide & 0.0268 & & \\
\hline \multicolumn{4}{|l|}{ M13 } \\
\hline Adherens junction assembly & $<0.001$ & Integrin signaling pathway & $<0.001$ \\
\hline Phosphatidylinositol phosphorylation & 0.0015 & Cadherin signaling pathway & $<0.001$ \\
\hline Vesicle-mediated transport & 0.0026 & & \\
\hline Positive regulation of protein localization to nucleus & 0.0043 & & \\
\hline Actin cytoskeleton organization & 0.0105 & & \\
\hline Cell differentiation & 0.0308 & & \\
\hline \multicolumn{4}{|l|}{ M14 } \\
\hline Positive regulation of $\mathrm{T}$ cell activation & 0.0035 & $\mathrm{~T}$ cell activation & $<0.001$ \\
\hline Interleukin-2-mediated signaling pathway & 0.0065 & Integrin signaling pathway & $<0.001$ \\
\hline Interleukin-4-mediated signaling pathway & 0.0065 & Angiogenesis & 0.0032 \\
\hline \multirow[t]{4}{*}{ Regulation of immune response } & 0.0430 & Toll like receptor signaling pathway & 0.0269 \\
\hline & & VEGF signaling pathway & 0.0387 \\
\hline & & $\mathrm{B}$ cell activation & 0.0387 \\
\hline & & Ras pathway & 0.0431 \\
\hline
\end{tabular}




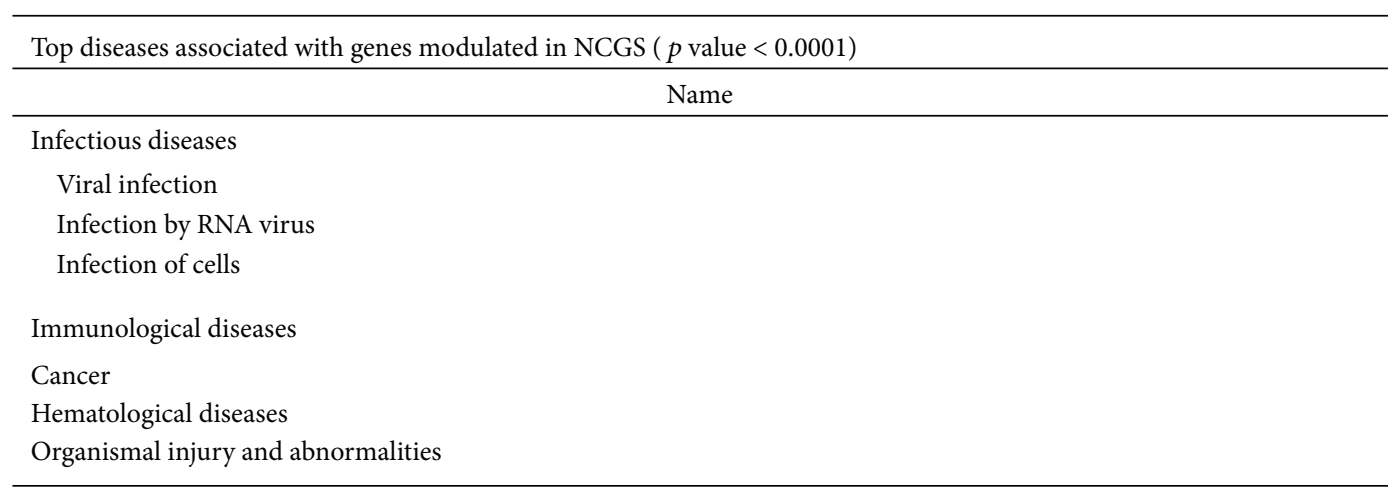

(a)

Genes modulated consistently with viral infection $(n=134)$
ACTR2, AES, AKTIP, ANXA5, AP1G2, AP2M1, ARF1, ARID1A, ATP6V0E1, BST2, BTG2, CALCOCO1, CCR4, CCT2,
CD165, CD44, CDK2, CLU, COPA, CREB1, CXCL10, CXCR6 DAZAP2, DDX17, DDX6, DHX9, DIAPH1, DNAJB1,
DNMT3A, DPP4, EEA1, ERI3, FBXW11, FCGR1A, FGFR2, FXR1, FYN, GBP1, GRK6, GTF2I, H3F3A, HIP1R, HIPK1,
HNRNPC, HNRNPH1, HNRNPM, HNRNPU, HSP90AA1, HSP90AB1, HSP90B1, HSPD1, HTATSF1, IFIH1, IKBKB,
IL15, IL18, IL1B, IRF7, JUN, KAT6A, KIF3A, LAMA2, LAPTM5, LARP1, LCK, LGALS1, LMNA, LPAR2, LRRAP1,
MAP2K2, MARK2, MAT2A, MVP, NEK9, NF2, P2RY10, PIK3R5, PIP5K1A, PLCG1, PMS1P1, POLR2A, PPM1D,
PPP4C, PRDM2, PRKCH, PRPF6, PYCARD, RAB2A, RAB6A, RAD21, RAD23A, RANBP2, RBM25, RBM5, RELA,
RPS10, RPS14, S100A8, SELPLG, SF3B1, SIGMAR1, SIKE1, SLAMF1, SLC4A7, SLFN12, SMAD3, SNRNP70, SOCS1,
SP110, SPEN, SPN, SPTAN1, SPTBN1, SRPK1, SRPK2, SRRM2, SRRT, STIP1, SUCLG2, TAGLN2, TBK1, TCF3, TECR,
TGBR2, TMEM63A, TMPO, TNFRF1B, TNFSF10, TNK1, TTC3, TWF1, UBE2H, ZBP1, ZNF480

(b)

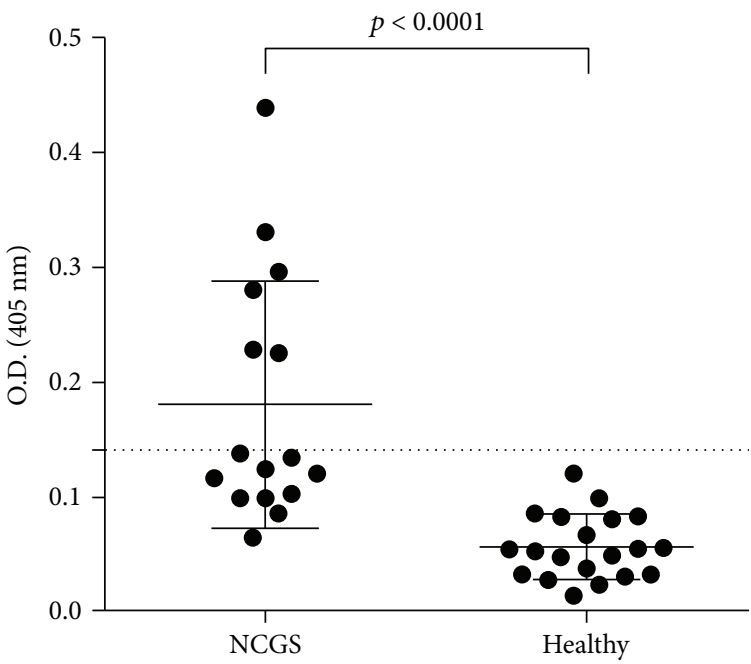

(c)

Figure 5: (a) List of diseases which are most likely to be statistically significantly associated and compatible with the transcriptional profile observed in NCGS. (b) DEGs in NCGS showing a modulation consistent with a viral infection process. (c) Detection of antibodies directed against the rotavirus VP7 peptide in the sera of patients with NCGS. Each circle represents a measurement for one patient, and the dashed horizontal line indicates the threshold for positivity (O.D. 0.140). The statistical $p$ value was calculated with the Mann-Whitney test $(p<0.0001)$.

gene modulated observed in NCGS, are the upregulation of members of the epidermal growth factor receptor (EGFR) signaling pathway and the concomitant downregulation of cell adhesion molecules beside a deregulation of ion transport. Noteworthy, the activation of EGFR signaling has been already observed in $\mathrm{CD}$ [36], and dysfunction of cell adhesion and transport are typical features of epithelial cells from active CD [37].

In this regard, it is worthwhile mentioning that patients with NCGS have normal to mildly inflamed mucosa (Marsh $0-1$ ), while partial or subtotal villous atrophy and crypt hyperplasia are hallmarks of CD. Nevertheless, we cannot 
TABLE 4: Selection of DEGs in NCGS that are also modulated in human T84 cells after stimulation with anti-VP7 rotavirus peptide antibodies.

\begin{tabular}{|c|c|c|c|c|}
\hline Gene symbol & Accession number & Gene title & FC NCGS PBCs & FC T84 treated cells \\
\hline \multicolumn{5}{|c|}{ Apoptosis } \\
\hline SOCS3 & NM_003955 & Suppressor of cytokine signaling 3 & 1.83 & 2.75 \\
\hline ANXA6 & NM_001155 & Annexin A6 & 1.57 & 2.72 \\
\hline SOS2 & NM_006939 & Son of sevenless homolog 2 (Drosophila) & 1.90 & 1.75 \\
\hline DEDD & AF064605 & Death effector domain containing & 1.78 & 1.47 \\
\hline \multicolumn{5}{|c|}{ Immune response } \\
\hline IFNA17 & NM_021268 & Interferon, alpha 17 & 1.59 & 1.56 \\
\hline IL6R & S72848 & Interleukin 6 receptor & 1.79 & 2.76 \\
\hline IRF5 & NM_03264335 & Interferon regulatory factor 5 & 1.52 & 1.52 \\
\hline CD84 & AF054818 & CD84 molecule & 2.55 & 3.40 \\
\hline \multicolumn{5}{|c|}{ Inflammatory response } \\
\hline IL1B & NM_000576 & Interleukin 1 , beta & 1.52 & 1.80 \\
\hline IL24 & NM_006850 & Interleukin 24 & 2.84 & 2.19 \\
\hline IL2RA & K03122 & Interleukin 2 receptor, alpha & 1.86 & 1.48 \\
\hline S100A8 & AW238654 & S100 calcium-binding protein A8 & 3.65 & 1.86 \\
\hline \multicolumn{5}{|c|}{ Cell proliferation } \\
\hline FGFR2 & NM_022975 & Fibroblast growth factor receptor 2 & 1.56 & 2.89 \\
\hline RAC2 & NM_002872 & Ras-related C3 botulinum toxin substrate 2 & 2.31 & 1.53 \\
\hline CDK2 & AB012305 & Cyclin-dependent kinase 2 & 1.63 & 1.78 \\
\hline DLG1 & AL121981 & Discs, large homolog 1 (Drosophila) & 1.57 & 1.74 \\
\hline \multicolumn{5}{|c|}{ Cell differentiation } \\
\hline GAS7 & BC006454 & Growth arrest-specific 7 & -2.03 & -1.90 \\
\hline SRD5A1 & NM_001047 & Steroid-5-alpha-reductase, alpha polypeptide 1 & -2.53 & -1.54 \\
\hline VAMP5 & NM_006634 & Vesicle-associated membrane protein 5 & -1.71 & -1.58 \\
\hline ZAK & NM_016653 & Sterile alpha motif and leucine zipper containing kinase AZK & -2.02 & -1.71 \\
\hline \multicolumn{5}{|c|}{ Cell-cell junctions } \\
\hline VCL & NM_014000 & Vinculin & -1.68 & -1.56 \\
\hline CTNND1 & NM_001331 & Catenin (cadherin-associated protein), delta 1 & -2.33 & -1.75 \\
\hline CTNNA1 & NM_001903 & Catenin (cadherin-associated protein), alpha $1,102 \mathrm{kDa}$ & -2.49 & -1.57 \\
\hline COL8A2 & NM_005202 & Collagen, type VIII, alpha 2 & -1.62 & -1.64 \\
\hline \multicolumn{5}{|c|}{ Metalloproteases } \\
\hline ADAM8 & AI814527 & ADAM metallopeptidase domain 8 & 1.94 & 1.57 \\
\hline ADAM9 & NM_003816 & ADAM metallopeptidase domain 9 & 2.81 & 1.48 \\
\hline ADAM17 & AI797833 & ADAM metallopeptidase domain 17 & 1.51 & 1.56 \\
\hline \multicolumn{5}{|c|}{ Receptors and signal transduction } \\
\hline IL2RA & K03122 & Interleukin 2 receptor, alpha & 1.86 & 1.48 \\
\hline IRF5 & NM_03264335 & Interferon regulatory factor 5 & 1.52 & 1.52 \\
\hline IL6R & S72848 & Interleukin 6 receptor & 1.79 & 2.76 \\
\hline \multicolumn{5}{|l|}{ Cytoskeleton } \\
\hline FGD6 & NM_018351 & FYVE, RhoGEF, and $\mathrm{pH}$ domain containing 6 & -2.40 & -1.48 \\
\hline ABLIM3 & NM_014945 & Actin-binding LIM protein family, member 3 & 1.86 & 1.49 \\
\hline PFN2 & NM_002628 & Profilin 2 & 1.51 & 1.47 \\
\hline \multicolumn{5}{|l|}{ Ion transport } \\
\hline SLC24A1 & AF026132 & Solute carrier family $24(\mathrm{Na} / \mathrm{K} / \mathrm{Ca}$ exchanger $)$, member 1 & 1.59 & 1.95 \\
\hline SLC30A1 & AI972416 & Solute carrier family 30 (zinc transporter), member 1 & 1.94 & 1.55 \\
\hline SLC4A4 & AF069510 & Solute carrier family $4, \mathrm{NaHCO}_{3}$ cotransporter, member 4 & 1.52 & 1.92 \\
\hline \multicolumn{5}{|c|}{ EGFR signaling pathway } \\
\hline AKT2 & NM_001626 & v-akt murine thymoma viral oncogene homolog 2 & 2.36 & 2.19 \\
\hline PIK3R1 & NM_181523 & Phosphoinositide-3-kinase, regulatory subunit 1 (alpha) & 2.76 & 1.54 \\
\hline PTPN12 & S69182 & Protein tyrosine phosphatase, nonreceptor type 12 & 2.27 & 1.50 \\
\hline
\end{tabular}


TABLE 5: Genes modulated in the three datasets playing a role in selected GO BPs related to the viral infection process.

\begin{tabular}{|c|c|c|}
\hline Gene symbol & Gene title & $\mathrm{FC}$ \\
\hline \multicolumn{3}{|l|}{ NCGS dataset } \\
\hline \multicolumn{3}{|c|}{ Viral transcription/gene expression } \\
\hline RANBP2 & RAN-binding protein 2 & 1.98 \\
\hline RPL27A & Ribosomal protein $\mathrm{L} 27 \mathrm{a}$ & 3.22 \\
\hline RPL37A & Ribosomal protein L37a & 2.94 \\
\hline RPLP2 & Ribosomal protein, large, P2 & 2.15 \\
\hline RPS10 & Ribosomal protein S10 & 2.66 \\
\hline RPS11 & Ribosomal protein S11 & 2.49 \\
\hline TPR & Translocated promoter region, nuclear basket protein & 4.40 \\
\hline \multicolumn{3}{|l|}{ Response to virus } \\
\hline RELA & v-rel reticuloendotheliosis viral oncogene homolog A (avian) & 1.54 \\
\hline IKBKB & Inhibitor of kappa light polypeptide gene enhancer in B cells, kinase beta & 2.69 \\
\hline IRF5 & Interferon regulatory factor 5 & 1.52 \\
\hline IFNA17 & Interferon, alpha 17 & 1.59 \\
\hline DDX3X & DEAD (Asp-Glu-Ala-Asp) box polypeptide 3, X-linked & 3.22 \\
\hline STAT2 & Signal transducer and activator of transcription $2,113 \mathrm{kDa}$ & 1.59 \\
\hline STAT1 & Signal transducer and activator of transcription $1,91 \mathrm{kDa}$ & 2.73 \\
\hline IRF3 & Interferon regulatory factor 3 & 1.67 \\
\hline DDX17 & DEAD (Asp-Glu-Ala-Asp) box helicase 17 & 4.75 \\
\hline \multicolumn{3}{|l|}{ Viral life cycle } \\
\hline TPR & Translocated promoter region, nuclear basket protein & 4.40 \\
\hline ATG16L1 & Autophagy-related 16-like 1 (S. cerevisiae) & 1.87 \\
\hline HSP90AB1 & Heat shock protein $90 \mathrm{kDa}$ alpha (cytosolic), class B member 1 & 1.87 \\
\hline RANBP2 & RAN-binding protein 2 & 1.98 \\
\hline DPP4 & Dipeptidyl-peptidase 4 & 1.61 \\
\hline DDX6 & DEAD (Asp-Glu-Ala-Asp) box helicase 6 & 4.70 \\
\hline HTATSF1 & HIV-1 Tat specific factor 1 & 2.23 \\
\hline SLAMF1 & Signaling lymphocytic activation molecule family member 1 & 1.65 \\
\hline \multicolumn{3}{|l|}{ T84 dataset } \\
\hline \multicolumn{3}{|c|}{ Viral transcription/gene expression } \\
\hline RPL27A & Ribosomal protein L27a & 1.68 \\
\hline RPS2 & Ribosomal protein S2 & 1.99 \\
\hline RPS6 & Ribosomal protein S6 & 1.51 \\
\hline \multicolumn{3}{|l|}{ Response to virus } \\
\hline IFIH1 & Interferon induced with helicase $\mathrm{C}$ domain 1 & 1.52 \\
\hline IFNA7 & Interferon, alpha 7 & 1.53 \\
\hline IFIT3 & Interferon-induced protein with tetratricopeptide repeats 3 & 1.46 \\
\hline IFNA4 & Interferon, alpha 4 & 1.73 \\
\hline IFI44 & Interferon-induced protein 44 & 1.46 \\
\hline IFNGR1 & Interferon gamma receptor 1 & 1.67 \\
\hline IFNA17 & Interferon, alpha 17 & 1.56 \\
\hline \multicolumn{3}{|l|}{ Viral life cycle } \\
\hline СТВР1 & C-terminal-binding protein 1 & 1.58 \\
\hline ADRBK1 & Adrenergic, beta, receptor kinase 1 & 1.46 \\
\hline HCRP1 & Hepatocellular carcinoma-related HCRP1 & 1.61 \\
\hline C9Orf28 & Chromosome 9 open reading frame 28 & 1.56 \\
\hline
\end{tabular}


TABle 5: Continued.

\begin{tabular}{|c|c|c|}
\hline Gene symbol & Gene title & FC \\
\hline \multicolumn{3}{|c|}{ Rotavirus infection dataset } \\
\hline \multicolumn{3}{|c|}{ Viral transcription/gene expression } \\
\hline NUP58 & Nucleoporin 58 kDa & 6.38 \\
\hline RPS16 & Ribosomal protein S16 & 2.10 \\
\hline DENR & Density-regulated protein & 2.11 \\
\hline \multicolumn{3}{|c|}{ Response to virus } \\
\hline XPR1 & Xenotropic and polytropic retrovirus receptor 1 & 1.72 \\
\hline CNOT7 & CCR4-NOT transcription complex subunit 7 & 3.54 \\
\hline CD40 & CD40 molecule, TNF receptor superfamily member 5 & 2.72 \\
\hline ITCH & Itchy E3 ubiquitin protein ligase & 2.26 \\
\hline ARF1 & ADP-ribosylation factor 1 & 1.91 \\
\hline BCL2L11 & BCL2-like 11 (apoptosis facilitator) & 3.21 \\
\hline BCL2L1 & BCL2-like 1 & 3.37 \\
\hline IKBKE & Inhibitor of kappa light polypeptide gene enhancer in B cells, kinase $\varepsilon$ & 1.50 \\
\hline DDX17 & DEAD (Asp-Glu-Ala-Asp) box helicase 17 & 2.13 \\
\hline \multicolumn{3}{|l|}{ Viral life cycle } \\
\hline NUP153 & Nucleoporin $153 \mathrm{kDa}$ & 2.01 \\
\hline VPS37A & Vacuolar protein sorting 37 homolog A (S. cerevisiae) & 1.90 \\
\hline XPR1 & Xenotropic and polytropic retrovirus receptor 1 & 1.72 \\
\hline UBB & Ubiquitin B & 1.75 \\
\hline ITCH & Itchy E3 ubiquitin protein ligase & 2.26 \\
\hline NUP58 & Nucleoporin $58 \mathrm{kDa}$ & 6.38 \\
\hline TNFRSF4 & Tumor necrosis factor receptor superfamily, member 4 & 1.94 \\
\hline SCARB2 & Scavenger receptor class B, member 2 & 1.96 \\
\hline
\end{tabular}

exclude that some NCGS patients, especially those positive for HLA-DQ2 and/or DQ8, may switch to classical CD in the course of the follow-up.

Since a large part of DEGs in the NCGS paralleled the modulation of genes seen in human T84 cells treated with antirotavirus Vp7 peptide antibodies, we next aimed at identifying the presence of such antibodies in sera of NCGS patients. We therefore tested in ELISA assay the sera from 16 NCGS patients and 20 healthy subjects for the detection of antirotavirus VP7 peptide antibodies. We found that these antibodies were present in 6 out of 16 (37\%) NCGS patients while were not detected in the sera of healthy subjects. Figure 5(c) shows that the levels of such antibodies are significantly different in the two set of tested samples $(p<0.0001)$. The detection of these antibodies in NCGS patients may be relevant to the pathogenesis of the NCGS given their ability to modulate sets of genes in intestinal epithelial cells as we previously demonstrated [6].

Taken together, the modulation of highly connected genes associated to the viral infection process and the presence of anti-VP7 antibodies in the sera of some NCGS patients may suggest that a link also exists between immune response to rotavirus infection and NCGS.

In this perspective, since anti-VP7 rotavirus antibodies are often present before the onset of CD, preceding the detection of celiac specific autoantibodies, [6] it is tempting to speculate that NCGS patients with CD genetic predisposition
(DQ2/DQ8) and presence of anti-VP7 antibodies may develop CD in the course of the follow-up.

Therefore, to further clarify the relationship between rotavirus infection and NCGS, we decided to perform an integrative bioinformatics analysis using the dataset GSE50628 downloaded from GEO (Gene Expression Omnibus) database (http://www.ncbi.nlm.nih.gov/geo/) that included samples of peripheral blood cells from patients affected by acute rotavirus infection (named in the paper "Rotavirus infection dataset"). This dataset was analysed to detect significantly modulated genes (Additional Table 2), and a comprehensive GO analysis was carried out on all datasets including NCGS, Rotavirus infection, and T84 datasets that we analysed in our previous work [6].

We then searched on the four datasets for the presence of genes associated to GO terms containing the words "virus" and/or "viral" and we found in all datasets a great number of such terms to which modulated genes were connected/related.

The searched terms explored a wide range of biological processes associated to viral infection from the entry of virus in the host cell, viral transcription and gene expression, modulation of host physiology by virus to cellular response to virus.

All the GO terms retrieved in the three datasets are listed in Additional Table 3. 
TABLE 6: Selection of genes modulated in human T84 cells after stimulation with anti-VP7 rotavirus peptide antibodies, involved in immune response and in molecular signaling related to the viral infection process.

\begin{tabular}{|c|c|c|}
\hline Gene symbol & Gene title & FC \\
\hline \multicolumn{3}{|c|}{ Immune response } \\
\hline CCR2 & Chemokine (C-C motif) receptor 2 & -1.48 \\
\hline CXCL1 & Chemokine (C-X-C motif) ligand 1 & 1.81 \\
\hline CXCL13 & Chemokine (C-X-C motif) ligand 13 & -5.52 \\
\hline GATA3 & GATA-binding protein 3 & -6.62 \\
\hline TROVE2 & TROVE domain family, member 2 & -1.64 \\
\hline ICOSLG & Inducible $\mathrm{T}$ cell costimulator ligand & 2.51 \\
\hline FCGR1A & Fc fragment of IgG, high affinity Ia, receptor (CD64) & 2.00 \\
\hline FOXP3 & Forkhead box P3 & 1.49 \\
\hline ULBP1 & UL16-binding protein 1 & -1.77 \\
\hline ITGA4 & Integrin, alpha 4 (antigen CD49D, alpha 4 subunit of VLA-4 receptor) & 1.48 \\
\hline CXCL9 & Chemokine (C-X-C motif) ligand 9 & 1.59 \\
\hline CSF3 & Colony-stimulating factor 3 (granulocyte) & 1.46 \\
\hline IL6 & Interleukin 6 (interferon, beta 2) & 1.51 \\
\hline CD84 & CD84 molecule & 3.40 \\
\hline FCGR2B & Fc fragment of IgG, low affinity IIb, receptor (CD32) & 1.77 \\
\hline LAT2 & Linker for activation of T cells family, member 2 & 1.85 \\
\hline C7 & Complement component 7 & 3.11 \\
\hline CCR1 & Chemokine (C-C motif) receptor 1 & 3.27 \\
\hline CCR3 & Chemokine (C-C motif) receptor 3 & 2.80 \\
\hline CFP & Complement factor properdin & 2.92 \\
\hline IL24 & Interleukin 24 & 2.19 \\
\hline IL8 & Interleukin 8 & 1.86 \\
\hline CXCL10 & Chemokine (C-X-C motif) ligand 10 & 1.82 \\
\hline IL1F7 & Interleukin 1 family, member 7 (zeta) & -2.26 \\
\hline IKBKB & Inhibitor of kappa light polypeptide gene enhancer in B cells, kinase beta & -2.25 \\
\hline CCL11 & Chemokine (C-C motif) ligand 11 & 1.96 \\
\hline \multicolumn{3}{|c|}{ Type I interferon signaling } \\
\hline \multicolumn{3}{|c|}{ Cellular response to interferon alpha } \\
\hline FCAR & Fc fragment of IgA, receptor for & 2.15 \\
\hline \multicolumn{3}{|c|}{ Type I interferon signaling } \\
\hline IFNA16 & Interferon, alpha 16 & 1.58 \\
\hline STAT1 & Signal transducer and activator of transcription $1,91 \mathrm{kDa}$ & -1.46 \\
\hline IFNA17 & Interferon, alpha 17 & 1.56 \\
\hline YY1 & YY1 transcription factor & -2.24 \\
\hline IFNA4 & Interferon, alpha 4 & 1.73 \\
\hline IRF8 & Interferon regulatory factor 8 interferon regulatory factor 8 & -1.68 \\
\hline IFNA5 & Interferon, alpha 5 & -2.85 \\
\hline IRF2 & Interferon regulatory factor 2 & 1.58 \\
\hline IFNA8 & Interferon, alpha 8 & 2.23 \\
\hline IRF5 & Interferon regulatory factor 5 & 1.52 \\
\hline IFI6 & Interferon, alpha-inducible protein 6 & 1.56 \\
\hline IFNA6 & Interferon, alpha 6 & 2.08 \\
\hline \multicolumn{3}{|c|}{ Positive regulation of interferon alpha production } \\
\hline IRF5 & Interferon regulatory factor 5 & 1.52 \\
\hline \multicolumn{3}{|c|}{ Positive regulation of interferon beta production } \\
\hline DDX3X & DEAD (Asp-Glu-Ala-Asp) box polypeptide 3, X-linked & -1.49 \\
\hline IRF5 & Interferon regulatory factor 5 & 1.52 \\
\hline \multicolumn{3}{|c|}{ Negative regulation of interferon beta production } \\
\hline LILRB1 & Leukocyte immunoglobulin-like receptor, subfamily B, member 1 & -1.60 \\
\hline
\end{tabular}


TABle 6: Continued.

\begin{tabular}{|c|c|c|}
\hline Gene symbol & Gene title & FC \\
\hline \multicolumn{3}{|c|}{ Positive regulation of Type I interferon production } \\
\hline IFI16 & Interferon, gamma-inducible protein 16 & -1.68 \\
\hline CREBBP & CREB-binding protein (Rubinstein-Taybi syndrome) & 1.51 \\
\hline \multicolumn{3}{|c|}{ Negative regulation of Type I interferon production } \\
\hline CYLD & Cylindromatosis (turban tumor syndrome) & -3.04 \\
\hline \multicolumn{3}{|c|}{ Gamma interferon signaling } \\
\hline \multicolumn{3}{|c|}{ Cellular response to Interferon Gamma signaling } \\
\hline FCAR & Fc fragment of IgA, receptor for & 2.15 \\
\hline $\mathrm{MRC1}$ & Mannose receptor, $\mathrm{C}$ type 1 & 2.52 \\
\hline SYNCRIP & Synaptotagmin-binding, cytoplasmic RNA-interacting protein & -1.69 \\
\hline CCL8 & chemokine (C-C motif) ligand 8 & 1.63 \\
\hline \multicolumn{3}{|c|}{ Interferon gamma signaling } \\
\hline STAT1 & Signal transducer and activator of transcription $1,91 \mathrm{kDa}$ & -1.46 \\
\hline MID1 & Midline 1 (Opitz/BBB syndrome) & -1.99 \\
\hline HLA-DRB4 & Major histocompatibility complex, class II, DR beta 4 & 2.39 \\
\hline SDK1 & Sidekick homolog 1 (chicken) & 1.61 \\
\hline IFNGR1 & Interferon gamma receptor 1 interferon gamma receptor 1 & 1.67 \\
\hline \multicolumn{3}{|c|}{ Negative regulation of gamma interferon production } \\
\hline LILRB1 & Leukocyte immunoglobulin-like receptor, subfamily B, member 1 & -1.60 \\
\hline CD244 & CD244 molecule, natural killer cell receptor 2B4 & -1.69 \\
\hline IL10 & Interleukin 10 & -3.56 \\
\hline \multicolumn{3}{|c|}{ Positive regulation of gamma interferon production } \\
\hline FOXP3 & Forkhead box P3 & 1.49 \\
\hline IL1B & Interleukin 1 , beta & 1.80 \\
\hline \multicolumn{3}{|c|}{ Toll-like receptor signaling } \\
\hline TANK & TRAF family member-associated NFKB activator & -1.91 \\
\hline CHUK & Conserved helix-loop-helix ubiquitous kinase & -1.72 \\
\hline ELK1 & ELK1, member of ETS oncogene family & 3.70 \\
\hline MAP3K8 & Mitogen-activated protein kinase kinase kinase 8 & -2.16 \\
\hline TLR6 & Toll-like receptor 6 & 2.43 \\
\hline TLR1 & Toll-like receptor 1 & 1.57 \\
\hline TLR7 & Toll-like receptor 7 & -1.64 \\
\hline MAP3K7 & Mitogen-activated protein kinase kinase kinase 7 & -1.89 \\
\hline LY96 & Lymphocyte antigen 96 & -1.81 \\
\hline NFKB2 & Nuclear factor of kappa light polypeptide gene enhancer in B cells 2 (p49/p100) & 1.54 \\
\hline REL & v-rel reticuloendotheliosis viral oncogene homolog (avian) & -1.82 \\
\hline PTGS2 & $\begin{array}{c}\text { Prostaglandin-endoperoxide synthase } 2 \text { (prostaglandin } \mathrm{G} / \mathrm{H} \text { synthase and } \\
\text { cyclooxygenase) }\end{array}$ & 1.76 \\
\hline TNFAIP3 & Tumor necrosis factor, alpha-induced protein 3 & 1.73 \\
\hline MAP2K3 & Mitogen-activated protein kinase kinase 3 & 1.59 \\
\hline IKBKB & Inhibitor of kappa light polypeptide gene enhancer in B cells, kinase beta & -2.25 \\
\hline TLR3 & Toll-like receptor 3 & -2.03 \\
\hline IFNB1 & Interferon, beta 1 , fibroblast & -1.84 \\
\hline IRAK3 & Interleukin-1 receptor-associated kinase 3 & 1.70 \\
\hline TLR4 & Toll-like receptor 4 & 1.46 \\
\hline IKBKE & Inhibitor of kappa light polypeptide gene enhancer in B cells, kinase epsilon & 2.06 \\
\hline MAP2K2 & Mitogen-activated protein kinase kinase 2 & 1.98 \\
\hline TLR2 & Toll-like receptor 2 & -2.30 \\
\hline
\end{tabular}


TABLE 7: Selection of genes modulated in PBCs in course of the acute phase of rotavirus infection, involved in immune response and in molecular signaling related to the viral infection process.

\begin{tabular}{|c|c|c|}
\hline Gene symbol & Gene title & FC \\
\hline \multicolumn{3}{|c|}{ Immune response } \\
\hline ADGRE3 & Adhesion G protein-coupled receptor E3;ADGRE3;ortholog & -3.35 \\
\hline ADIPOQ & Adiponectin, $\mathrm{C} 1 \mathrm{Q}$ and collagen domain containing & -1.60 \\
\hline BLK & BLK proto-oncogene, Src family tyrosine kinase & 1.72 \\
\hline BRAF & B-Raf proto-oncogene, serine/threonine kinase & 1.57 \\
\hline BTK & Bruton agammaglobulinemia tyrosine kinase & -1.59 \\
\hline C1QTNF9 & $\mathrm{C} 1 \mathrm{q}$ and tumor necrosis factor related protein 9 & -1.69 \\
\hline CD109 & CD109 molecule & -1.84 \\
\hline CD79B & CD79b molecule, immunoglobulin-associated beta & -1.67 \\
\hline CLEC7A & C-type lectin domain family 7 , member A & -1.62 \\
\hline CMIP & c-Maf inducing protein & -3.50 \\
\hline CSF2RA & Colony-stimulating factor 2 receptor, alpha, low-affinity (granulocyte-macrophage) & -2.30 \\
\hline CXCL2 & Chemokine (C-X-C motif) ligand 2 & -3.76 \\
\hline CXCL8 & Chemokine (C-X-C motif) ligand 8 & -8.65 \\
\hline FCER1A & Fc fragment of IgE, high affinity I, receptor for; alpha polypeptide & -5.64 \\
\hline HCST & Hematopoietic cell signal transducer & 1.85 \\
\hline IL18BP & Interleukin 18 binding protein & 1.56 \\
\hline JAG1 & Jagged 1 & -2.06 \\
\hline KLRB1 & Killer cell lectin-like receptor subfamily B, member 1 & -5.99 \\
\hline MAP3K11 & Mitogen-activated protein kinase kinase kinase 11 & 1.55 \\
\hline MASP1 & Mannan-binding lectin serine peptidase 1 & -1.50 \\
\hline MR1 & Major histocompatibility complex, class I-related & 8.43 \\
\hline PLEKHN1 & Pleckstrin homology domain containing, family $\mathrm{N}$ member 1 & -1.99 \\
\hline PPP2R2C & Protein phosphatase 2, regulatory subunit $\mathrm{B}$, gamma & -1.84 \\
\hline PPP3CA & Protein phosphatase 3 , catalytic subunit, alpha isozyme & -1.89 \\
\hline PSME3 & Proteasome activator subunit 3 & 1.91 \\
\hline PVR & Poliovirus receptor & -1.59 \\
\hline STAT5B & Signal transducer and activator of transcription 5B & -2.06 \\
\hline TNFRSF10C & Tumor necrosis factor receptor superfamily, member $10 \mathrm{c}$ decoy without an intracellular domain & -1.75 \\
\hline TNFRSF4 & Tumor necrosis factor receptor superfamily, member 4 & 1.94 \\
\hline \multicolumn{3}{|c|}{ Type I interferon signaling } \\
\hline \multicolumn{3}{|c|}{ Positive regulation of Type I interferon production } \\
\hline EP300 & E1A-binding protein $\mathrm{p} 300$ & -1.56 \\
\hline POLR3G & Polymerase (RNA) III (DNA directed) polypeptide G (32kD) & -1.98 \\
\hline CREBBP & CREB-binding protein & -1.83 \\
\hline LRRFIP1 & Leucine rich repeat (in FLII) interacting protein 1 & -2.14 \\
\hline SOCS1 & Suppressor of cytokine signaling 1 & 2.32 \\
\hline \multicolumn{3}{|c|}{ Negative regulation of Type I interferon production } \\
\hline UBB & Ubiquitin B & 1.75 \\
\hline ITCH & Itchy E3 ubiquitin protein ligase & 2.26 \\
\hline TAX1BP1 & Tax1 (human $\mathrm{T}$ cell leukemia virus type $\mathrm{I}$ ) binding protein 1 & -4.01 \\
\hline \multicolumn{3}{|c|}{ Negative regulation of Type I interferon pathway } \\
\hline PTPN2 & Protein tyrosine phosphatase, nonreceptor type 2 & 2.10 \\
\hline \multicolumn{3}{|c|}{ Positive regulation of interferon beta production } \\
\hline ZBTB20 & Zinc finger and BTB domain containing 20 & 4.27 \\
\hline \multicolumn{3}{|c|}{ Negative regulation of interferon Beta production } \\
\hline PTPRS & Protein tyrosine phosphatase, receptor type, $S$ & -2.00 \\
\hline CACTIN & Cactin, spliceosome C complex subunit & -2.53 \\
\hline
\end{tabular}


TABLe 7: Continued.

Gene symbol
Cellular response to interferon alpha
TPR

Negative regulation of interferon alpha production PTPRS Protein tyrosine phosphatase, receptor type, $S$

Type I interferon signaling pathway

JAK1

Janus kinase 1

1.79

IFI27

IFI27L2

Interferon, alpha-inducible protein 27

75.26

Interferon, alpha-inducible protein 27-like $2 \quad-1.59$

IKBKE

Inhibitor of kappa light polypeptide gene enhancer in B cells, kinase epsilon

1.50

TPR

Translocated promoter region, nuclear basket protein

$-2.55$

Positive regulation of Type I interferon pathway

MME

Membrane metallo-endopeptidase

$-5.54$

Gamma interferon signaling

JAK1

Janus kinase 1

1.79

HLADQB1

Major histocompatibility complex, class II, DQ beta 1

$-36.43$

HLADQA1

Major histocompatibility complex, class II, DQ alpha 1

$-37.95$

PIAS3

Protein inhibitor of activated STAT 3

2.11

HLADRB1

Major histocompatibility complex, class II, DR beta 1

$-10.91$

MAPK8

Mitogen-activated protein kinase 8

$-2.28$

MAPK1

Mitogen-activated protein kinase 1

$-2.23$

Regulation of interferon gamma signaling pathway

PTPN2

Protein tyrosine phosphatase, nonreceptor type 2

Positive regulation of interferon gamma production

PDE4B

Phosphodiesterase 4B, cAMP-specific

$-1.77$

ZFPM1

Zinc finger protein, FOG family member 1

Negative regulation of interferon gamma production

HLADRB1

RARA

FOXP3

Cellular response to interferon gamma

SLC26A6

DAPK3

CD40

MEFV

SNCA

MRC1

Toll-like receptors signaling pathway

TANK

NFKBIA

MAPK8

IKBKE

MAPK1

JUN

Major histocompatibility complex, class II, DR beta $1 \quad-10.91$

Retinoic acid receptor, alpha $\quad-7.60$

Forkhead box P3 $\quad-2.14$

Solute carrier family 26 (anion exchanger), member $6 \quad 1.95$

Death-associated protein kinase $3 \quad-1.62$

CD40 molecule, TNF receptor superfamily member $5 \quad 2.72$

Mediterranean fever $\quad-4.83$

$\begin{array}{lc}\text { Synuclein alpha } & 8.62\end{array}$

Mannose receptor, C type $1 \quad-1.93$

TRAF family member-associated NFKB activator $\quad-1.91$

$-1.76$

$-2.28$

1.50

$-2.23$

$-1.91$

Table 5 shows selected genes modulated in the three datasets that are ascribed to the most representative GO terms, including viral transcription, viral gene expression, response to virus, viral genome replication, and viral life cycle.
Moreover, the GO analysis of the abovementioned datasets was complemented by searching for transcripts involved in immune response.

In the "T84 dataset," we found upregulation for the T cell costimulatory molecule ICOSLG, the transcriptional 
regulator that is crucial for the development and inhibitory function of regulatory $\mathrm{T}$ cells, [38] interleukin-6 that is pivotal for the development of Th-17 cells [39], and FCGR2B that is involved in the phagocytosis of immune complexes and in modulation of antibody production by B cells [40] (Table 6).

In the "Rotavirus infection" dataset, we found upregulation for molecules that are crucial in the immune response including the BLK gene, involved in transmitting signals through surface immunoglobulins, supporting the pro-B to pre-B transition, [41] MR1/MAIT playing a role in the development of the mucosal-associated invariant $\mathrm{T}$ cells (MAIT), [42] TNFRSF4 involved in T cell proliferation [43], and HCST/DAP10 playing a role in triggering cytotoxicity against both stressed and infected by virus target cells [44] (Table 7).

Interestingly, in all the datasets, we found the presence of modulated genes involved in the type I interferon signaling, that is central in autoimmunity, and in molecular pathways involved in the immune response to viral infection, including the Toll-like receptors, and the type I and gamma interferon pathways (see Tables 2, 6, and 7).

Taken together, our data seem to indicate that NCGS has features of autoimmunity and that an immune response to rotavirus may play a role in some cases of NCGS.

\section{Conclusions}

NCGS is an emerging new clinical entity lacking specific diagnostic biomarkers which has been reported to occur in $6-10 \%$ of the population. Interestingly, up to $50 \%$ of these patients carry HLA-DQ2 and/or HLA-DQ8 genes. NCGS patients may complain gastrointestinal (e.g., diarrhoea/constipation, abdominal pain, bloating) and/or extraintestinal symptoms ("foggy mind," headache, dermatitis, etc.) which recede with GFD. The pathogenesis of NCGS is still unclear and the data, so far obtained, suggest a predominant activation of the innate immune responses.

Our data indicate a concomitant involvement of the adaptive immune system and suggest that NCGS may have an autoimmune origin. This is based both on gene expression data (i.e., TH17-IFNA I signatures) and on the presence of TH17 cells and of serological markers of autoimmunity in NCGS. Our results also indicate a possible involvement of rotavirus infection in the pathogenesis of NCGS, similarly to what we have previously shown in CD.

\section{Conflicts of Interest}

The authors declare that there is no conflict of interest regarding the publication of this paper.

\section{Authors' Contributions}

Antonio Puccetti, Daniele Saverino, Roberta Opri, Claudio Lunardi, and Marzia Dolcino equally contributed to this paper.

\section{Supplementary Materials}

Supplementary 1. Additional Table 1: genes modulated in NGCS samples versus healthy controls.

Supplementary 2. Additional Table 2: genes modulated in the "Rotavirus infection" dataset.

Supplementary 3. Additional Table 3: GO terms containing the words "virus" and "viral" to which are associated genes modulated in the three datasets.

\section{References}

[1] U. Volta and R. De Giorgio, "New understanding of gluten sensitivity," Nature Reviews Gastroenterology \& Hepatology, vol. 9, no. 5, pp. 295-299, 2012.

[2] G. Caio, G. Riegler, M. Patturelli, A. Facchiano, L. de Magistris, and A. Sapone, "Pathophysiology of non-celiac gluten sensitivity: where are we now?," Minerva Gastroenterologica e Dietologica, vol. 63, no. 1, pp. 16-21, 2017.

[3] P. H. Dennehy, "Rotavirus infection: a disease of the past?" Infectious Disease Clinics of North America, vol. 29, no. 4, pp. 617-635, 2015.

[4] J. B. Pesavento, S. E. Crawford, M. K. Estes, and B. V. Prasad, "Rotavirus proteins: structure and assembly," Current Topics in Microbiology and Immunology, vol. 309, pp. 189-219, 2006.

[5] G. Zanoni, R. Navone, C. Lunardi et al., "In celiac disease, a subset of autoantibodies against transglutaminase binds tolllike receptor 4 and induces activation of monocytes," PLoS Medicine, vol. 3, no. 9, article e358, 2006.

[6] M. Dolcino, G. Zanoni, C. Bason et al., "A subset of antirotavirus antibodies directed against the viral protein vp7 predicts the onset of celiac disease and induces typical features of the disease in the intestinal epithelial cell line t84," Immunologic Research, vol. 56, no. 2-3, pp. 465-476, 2013.

[7] C. Lunardi, C. Bason, R. Navone et al., "Systemic sclerosis immunoglobulin $g$ autoantibodies bind the human cytomegalovirus late protein ul94 and induce apoptosis in human endothelial cells," Nature Medicine, vol. 6, no. 10, pp. 1183-1186, 2000.

[8] M. S. Cline, M. Smoot, E. Cerami et al., "Integration of biological networks and gene expression data using cytoscape," Nature Protocols, vol. 2, no. 10, pp. 2366-2382, 2007.

[9] G. D. Bader and C. W. Hogue, "An automated method for finding molecular complexes in large protein interaction networks," BMC Bioinformatics, vol. 4, no. 1, p. 2, 2003.

[10] M. Dolcino, A. Ottria, A. Barbieri et al., "Gene expression profiling in peripheral blood cells and synovial membranes of patients with psoriatic arthritis," PLoS One, vol. 10, no. 6, article e0128262, 2015.

[11] M. Dolcino, G. Patuzzo, A. Barbieri et al., "Gene expression profiling in peripheral blood mononuclear cells of patients with common variable immunodeficiency: modulation of adaptive immune response following intravenous immunoglobulin therapy," PLoS One, vol. 9, no. 5, article e97571, 2014.

[12] C. Lunardi, M. Dolcino, D. Peterlana et al., “Antibodies against human cytomegalovirus in the pathogenesis of systemic sclerosis: a gene array approach," PLoS Medicine, vol. 3, no. 1, article e2, 2005. 
[13] J. Zhou, H. K. Law, C. Y. Cheung, I. H. Ng, J. S. Peiris, and Y. L. Lau, "Functional tumor necrosis factor-related apoptosisinducing ligand production by avian influenza virus-infected macrophages," The Journal of Infectious Diseases, vol. 193, no. 7, pp. 945-953, 2006.

[14] L. D. Heftdal, K. Stengaard-Pedersen, L. M. Ornbjerg et al., "Soluble cd206 plasma levels in rheumatoid arthritis reflect decrease in disease activity," Scandinavian Journal of Clinical and Laboratory Investigation, vol. 77, no. 5, pp. 385-389, 2017.

[15] T. Areschoug and S. Gordon, "Scavenger receptors: role in innate immunity and microbial pathogenesis," Cellular Microbiology, vol. 11, no. 8, pp. 1160-1169, 2009.

[16] N. Rother and J. van der Vlag, "Disturbed T cell signaling and altered Th17 and regulatory T cell subsets in the pathogenesis of systemic lupus erythematosus," Frontiers in Immunology, vol. 6, p. 610, 2015.

[17] E. Lubberts, "The IL-23-IL-17 axis in inflammatory arthritis," Nature Reviews Rheumatology, vol. 11, no. 10, p. 562, 2015.

[18] M. Diani, G. Altomare, and E. Reali, "T helper cell subsets in clinical manifestations of psoriasis," Journal of Immunology Research, vol. 2016, Article ID 7692024, 7 pages, 2016.

[19] R. A. Gordon, G. Grigoriev, A. Lee, G. D. Kalliolias, and L. B. Ivashkiv, "The interferon signature and Stat1 expression in rheumatoid arthritis synovial fluid macrophages are induced by tumor necrosis factor $\alpha$ and counter-regulated by the synovial fluid microenvironment," Arthritis \& Rheumatism, vol. 64, no. 10, pp. 3119-3128, 2012.

[20] A. Nzeusseu Toukap, C. Galant, I. Theate et al., "Identification of distinct gene expression profiles in the synovium of patients with systemic lupus erythematosus," Arthritis \& Rheumatism, vol. 56, no. 5, pp. 1579-1588, 2007.

[21] R. M. Thurlings, M. Boumans, J. Tekstra et al., "Relationship between the type I interferon signature and the response to rituximab in rheumatoid arthritis patients," Arthritis \& Rheumatism, vol. 62, no. 12, pp. 3607-3614, 2010.

[22] H. G. Raterman, S. Vosslamber, S. de Ridder et al., "The interferon type I signature towards prediction of non-response to rituximab in rheumatoid arthritis patients," Arthritis Research \& Therapy, vol. 14, no. 2, p. R95, 2012.

[23] F. Moschella, G. F. Torelli, M. Valentini et al., "Cyclophosphamide induces a type I interferon-associated sterile inflammatory response signature in cancer patients' blood cells: implications for cancer chemoimmunotherapy," Clinical Cancer Research, vol. 19, no. 15, pp. 4249-4261, 2013.

[24] N. I. Maria, Z. Brkic, M. Waris et al., "MxA as a clinically applicable biomarker for identifying systemic interferon type I in primary Sjögren's syndrome," Annals of the Rheumatic Diseases, vol. 73, no. 6, pp. 1052-1059, 2014.

[25] G. Caignard, M. Lucas-Hourani, K. P. Dhondt et al., “The V protein of Tioman virus is incapable of blocking type I interferon signaling in human cells," PLoS One, vol. 8, no. 1, article e53881, 2013.

[26] Z. Brkic, O. B. Corneth, M. A. Versnel, and E. Lubberts, "Response to 'T-helper 17 cell cytokines and interferon type I: partners in crime in systemic lupus erythematosus?' authors' reply," Arthritis Research \& Therapy, vol. 16, no. 3, p. $410,2014$.

[27] J. J. O'Shea and R. Plenge, "JAK and Stat signaling molecules in immunoregulation and immune-mediated disease," Immunity, vol. 36, no. 4, pp. 542-550, 2012.
[28] A. F. Heneghan, J. F. Pierre, and K. A. Kudsk, "JAK-STAT intestinal mucosal immunology," JAK-STAT, vol. 2, no. 4, article e25530, 2013.

[29] A. Sapone, K. M. Lammers, V. Casolaro et al., "Divergence of gut permeability and mucosal immune gene expression in two gluten-associated conditions: celiac disease and gluten sensitivity," BMC Medicine, vol. 9, no. 1, p. 23, 2011.

[30] N. Schlegel, M. Meir, V. Spindler, C. T. Germer, and J. Waschke, "Differential role of Rho GTPases in intestinal epithelial barrier regulation in vitro," Journal of Cellular Physiology, vol. 226, no. 5, pp. 1196-1203, 2011.

[31] A. Banan, J. Z. Fields, Y. Zhang, and A. Keshavarzian, "Phospholipase c- $\gamma$ inhibition prevents egf protection of intestinal cytoskeleton and barrier against oxidants," American Journal of Physiology Gastrointestinal and Liver Physiology, vol. 281, no. 2, pp. G412-G423, 2001.

[32] D. Smyth, V. Phan, A. Wang, and D. M. McKay, "Interferon$\gamma$-induced increases in intestinal epithelial macromolecular permeability requires the Src kinase Fyn," Laboratory Investigation, vol. 91, no. 5, pp. 764-777, 2011.

[33] R. Shtrichman and C. E. Samuel, "The role of gamma interferon in antimicrobial immunity," Current Opinion in Microbiology, vol. 4, no. 3, pp. 251-259, 2001.

[34] L. C. Stene, M. C. Honeyman, E. J. Hoffenberg et al., "Rotavirus infection frequency and risk of celiac disease autoimmunity in early childhood: a longitudinal study," The American Journal of Gastroenterology, vol. 101, no. 10, pp. 2333-2340, 2006.

[35] B. Diosdado, E. van Oort, and C. Wijmenga, “"Coelionomics”: towards understanding the molecular pathology of coeliac disease," Clinical Chemistry and Laboratory Medicine, vol. 43, no. 7, pp. 685-695, 2005.

[36] K. Juuti-Uusitalo, M. Maki, H. Kainulainen, J. Isola, and K. Kaukinen, "Gluten affects epithelial differentiationassociated genes in small intestinal mucosa of coeliac patients," Clinical \& Experimental Immunology, vol. 150, no. 2, pp. 294305, 2007.

[37] S. Bracken, G. Byrne, J. Kelly, J. Jackson, and C. Feighery, "Altered gene expression in highly purified enterocytes from patients with active coeliac disease," BMC Genomics, vol. 9, no. 1, p. 377, 2008.

[38] S. Sakaguchi, M. Miyara, C. M. Costantino, and D. A. Hafler, "Foxp $3^{+}$regulatory $\mathrm{T}$ cells in the human immune system," Nature Reviews Immunology, vol. 10, no. 7, pp. 490-500, 2010.

[39] C. Zhang, X. Zhang, and X. H. Chen, "Inhibition of the interleukin-6 signaling pathway: a strategy to induce immune tolerance," Clinical Reviews in Allergy \& Immunology, vol. 47, no. 2, pp. 163-173, 2014.

[40] M. R. Clatworthy, "B-cell regulation and its application to transplantation," Transplant International, vol. 27, no. 2, pp. 117-128, 2014.

[41] R. C. Hsueh and R. H. Scheuermann, "Tyrosine kinase activation in the decision between growth, differentiation, and death responses initiated from the B cell antigen receptor," Advances in Immunology, vol. 75, pp. 283-316, 2000.

[42] C. R. Shaler, J. Choi, P. T. Rudak et al., "MAIT cells launch a rapid, robust and distinct hyperinflammatory response to bacterial superantigens and quickly acquire an anergic phenotype that impedes their cognate antimicrobial function: defining a novel mechanism of superantigen-induced immunopathology and immunosuppression," PLoS Biology, vol. 15, no. 6, article e2001930, 2017. 
[43] T. H. Schreiber, D. Wolf, M. Bodero, L. Gonzalez, and E. R. Podack, "T cell costimulation by TNFR superfamily (TNFRSF) 4 and TNFRSF25 in the context of vaccination," The Journal of Immunology, vol. 189, no. 7, pp. 3311-3318, 2012.

[44] I. Kavazović, M. Lenartić, V. Jelenčić et al., "NKG2D stimulation of $\mathrm{CD}^{+} \mathrm{T}$ cells during priming promotes their capacity to produce cytokines in response to viral infection in mice," European Journal of Immunology, vol. 47, no. 7, pp. 11231135, 2017. 


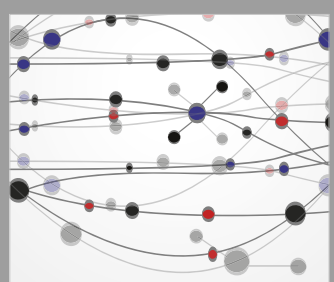

The Scientific World Journal
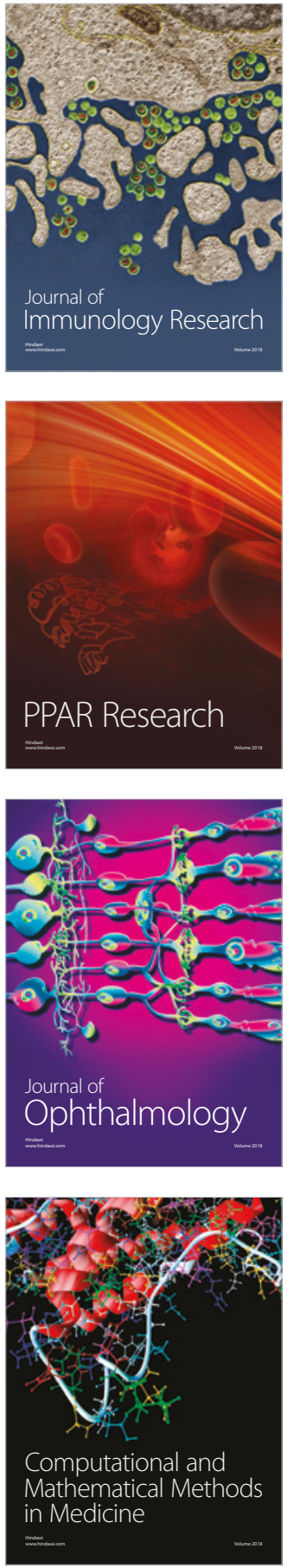

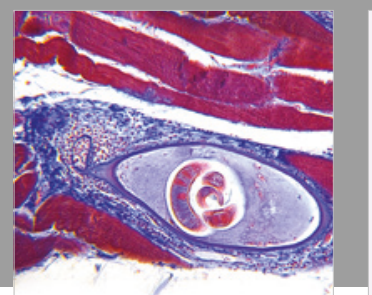

Gastroenterology Research and Practice

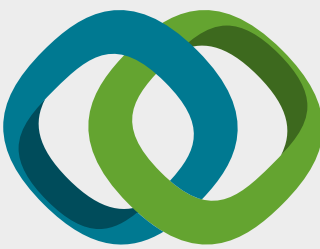

\section{Hindawi}

Submit your manuscripts at

www.hindawi.com
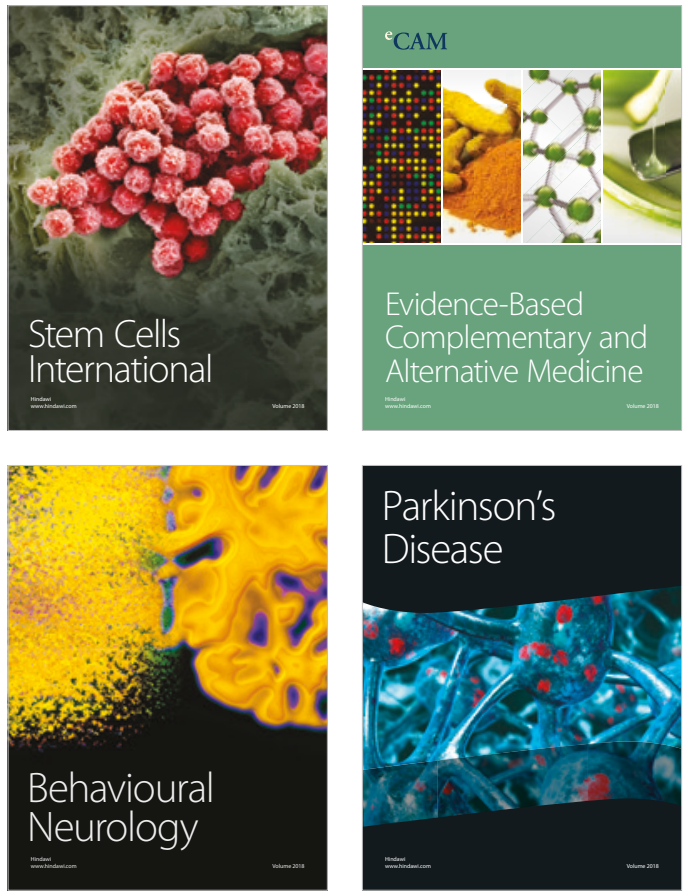

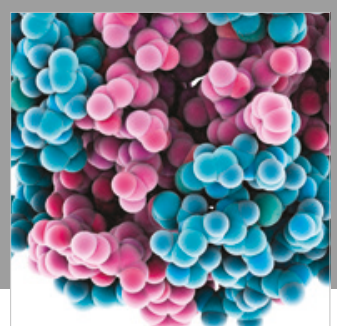

ournal of

Diabetes Research

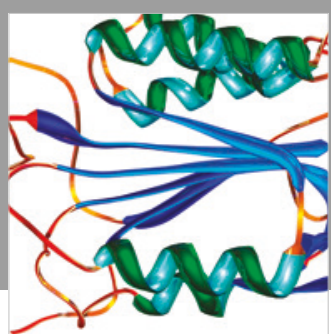

Disease Markers
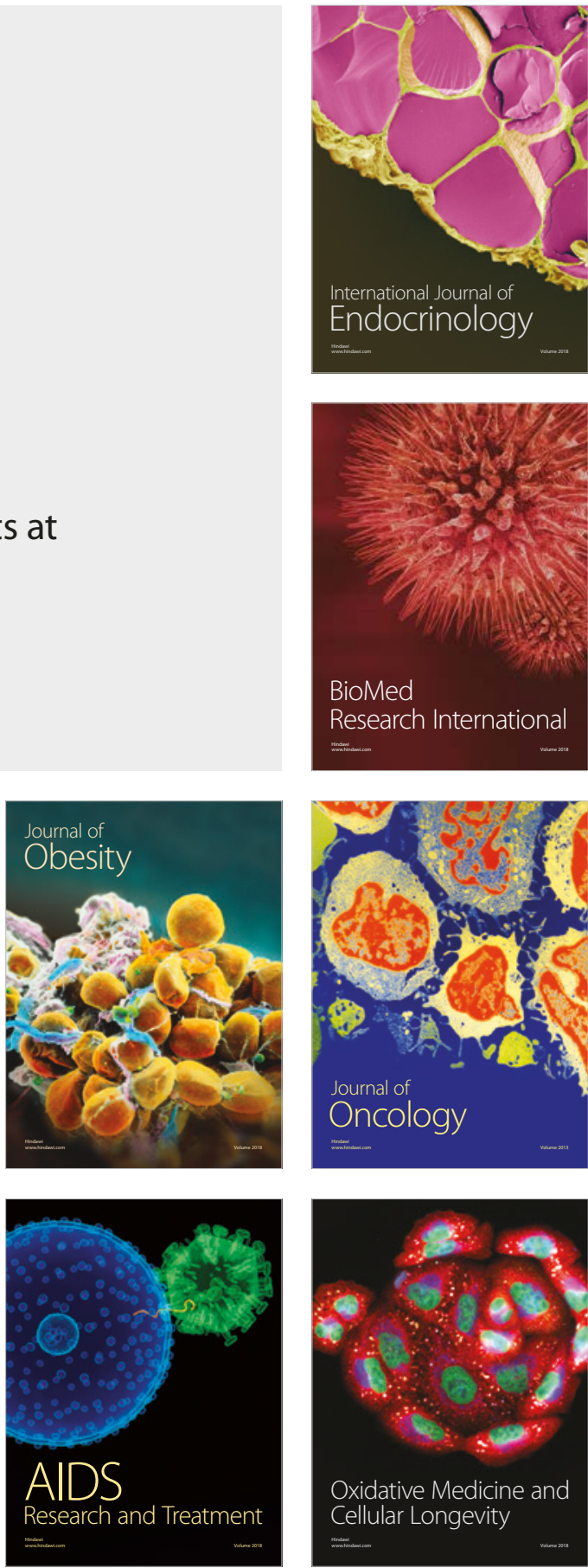